This PDF is a selection from a published volume from the National Bureau of Economic Research

Volume Title: The Economics of Poverty Traps

Volume Authors/Editors: Christopher B. Barrett, Michael R. Carter, and Jean-Paul Chavas, editors

Volume Publisher: University of Chicago Press

Volume ISBNs: 978-0-226-57430-1 (cloth); 978-0-226-57444-8

(electronic); 0-226-57430-X (cloth)

Volume URL: http://www.nber.org/books/barr-3

Conference Date: June 28-29, 2016

Publication Date: December 2018

Chapter Title: Poverty and Cognitive Function

Chapter Author(s): Emma Boswell Dean, Frank Schilbach, Heather Schofield

Chapter URL: http://www.nber.org/chapters/c13830

Chapter pages in book: (p. $57-118)$ 


\title{
Poverty and Cognitive Function
}

\author{
Emma Boswell Dean, Frank Schilbach, and \\ Heather Schofield
}

\subsection{Introduction}

Economic growth has lifted billions out of poverty in the span of a few generations. Despite these positive trends, poverty remains entrenched for millions around the globe. One long-standing explanation for poverty's persistence is the possibility of poverty traps, or self-reinforcing cycles of poverty. Theoretical models of such poverty traps - often centered on nutrition in the earliest cases - have been central in the development literature for over half a century (Leibenstein 1957; Mirrlees 1975; Stiglitz 1976; Bliss and Stern 1978; Dasgupta and Ray 1986). This literature has expanded in many directions to consider the varying potential underlying forces such as geographic characteristics, pecuniary externalities, and even cultural forces, as well as both theoretical and policy implications of such traps, ranging from intergenerational transmission of poverty to equilibrium unemployment (Jalan and Ravallion 2002; Sachs 2005; Fang and Loury 2005; Currie and Almond 2011; Barrett and Carter 2013; Sachs 2014; Kraay and Raddatz 2007).

Emma Boswell Dean is assistant professor at the University of Miami. Frank Schilbach is assistant professor of economics at the Massachusetts Institute of Technology, a JPAL affiliate, and a faculty research fellow of the National Bureau of Economic Research. Heather Schofield is assistant professor in the Perelman School of Medicine and the Wharton School of the University of Pennsylvania.

We thank participants at the NBER conference, John Hoddinott, Joshua Dean, and our anonymous referee for insightful comments and suggestions. We are also grateful for excellent research assistance from Jordan Browne, Stephanie Chan, Sarah Quinn, and Alicia Weng. We also thank Emily Gallagher and Lesley Fowler for their meticulous editing and helpful suggestions. All remaining errors are our own. For acknowledgments, sources of research support, and disclosure of the authors' material financial relationships, if any, please see http://www .nber.org/chapters/c13830.ack. 
Despite the extensive literature in this area and the policy appeal of potentially instigating virtuous and self-reinforcing cycles of income growth and wealth, the empirical evidence that such traps exist remains mixed (Banerjee and Duflo 2011; Kraay and McKenzie 2014; Barrett, Garg, and McBride 2016). Moreover, even in the instances where actual evidence is consistent with such traps, their exact mechanisms remain unclear (Banerjee et al. 2015; Bandiera et al. 2015). This chapter focuses on one potential underlying mechanism that has yet to be explored in depth, cognitive function.

Poverty may affect cognitive function in a variety of ways. Evidence is beginning to accumulate that cognitive functions are limited resources that can be strained by living in poverty (Schilbach, Schofield, and Mullainathan 2016). Being forced to make constant trade-offs with limited resources can act as a "load" on cognitive function (Mullainathan and Shafir 2013). Further, poverty can affect economic behavior via psychological effects including stress and negative affective states, such as depression (Haushofer and Fehr 2014). In addition to directly capturing individuals' minds, poverty often entails a number of material deprivations that may further impede cognitive function. Perhaps most well known among these deprivations is malnutrition. One in seven individuals around the world remain below recommended levels of caloric intake (Food and Agricultural Organization of the United Nations et al. 2011). Moreover, in many settings, the poor are exposed to sleep deprivation, physical pain, and substance abuse at alarming levels. While research is still in progress, to date we have found that the poor in Chennai, India, sleep just over five hours per night, with more than twenty disruptions on average, using objective measurements from wristwatch-like actigraphs. Similarly remarkable, a survey of 1,200 low-income informal labor market participants revealed an average pain level of 5 at the end of the workday, on a 0 to 10 scale. Moreover, the majority of male low-income workers in Chennai drink daily, consuming an average of over five standard drinks per day and spending over 20 percent of their daily labor incomes on alcohol (Schilbach 2017). Each of these correlates of poverty have been shown to tax cognitive resources (Schofield 2014; Lim and Dinges 2010; Moriarty, McGuire, and Finn 2011; Steele and Josephs 1990).

The resulting reductions in these cognitive resources may have broad feedback effects on earnings and wealth, ranging from occupational choice to technology adoption, consumption patterns, and risk and time preferences. In other words, the relationship between cognitive function and poverty could be bidirectional, generating the potential for feedback loops, reduced mobility, and - if the resulting effects are large enough - poverty traps. The goal of this chapter is to highlight the potential interplay between cognitive function and poverty and, in doing so, to facilitate further study of this potential bidirectional mechanism by providing a "primer for economists" on areas of cognitive function, their measurement, and their potential implications for poverty. 
Despite the potential importance of cognitive function in the lives of the poor, there are several challenges for understanding its causes and consequences. First, both the factors impeding cognitive function and the downstream effects of reduced cognitive function are likely to be diffuse, making measurement of channels and feedback effects challenging. Second, while some of the impacts of poverty on cognitive function are immediate (e.g., via acute physical pain), other impacts (e.g., via sleep deprivation or nutrition) are slow-moving and cumulative, making them even more challenging to detect, both for researchers and individuals themselves. Third, existing measurements of many of the channels discussed in this chapter are limited. For instance, data on sleeping patterns in developing countries is scarce and often limited to self-reports, which are likely to be inaccurate (Lauderdale et al. 2008). Yet, although these challenges exist, careful design and improved measurement technologies make them surmountable, opening the door to a wide variety of high-value studies.

Beyond a potential role in creating feedback loops that increase the persistence of poverty, an enhanced understanding of the psychological or cognitive lives of the poor is, in and of itself, of substantial value. Improved understanding of the financial lives of the poor over the previous few decades has generated many insights; for example, the wealth of data from financial diaries has shed light on the incredible complexity of the financial lives of the poor - with those in poverty often balancing a dizzying array of transactions, income streams, and debts. These data have helped to greatly enhance our understanding of financial behaviors among the poor. Similarly, as methods to study cognitive function at scale improve, and as there is increased acceptance of the idea that limits on cognition may influence economic decision-making, there is significant potential to improve our understanding of the psychological lives of the poor, with many broad consequences across countless aspects of lives of the poor.

The remainder of this chapter is structured as follows. Section 2.2 begins with a concise overview of cognitive functions for economists, including definitions and descriptions of four key areas with potential importance for economic decision-making. In addition, this section discusses how to measure the different aspects of cognitive function in order to quantify potential effects of poverty and to facilitate further research in this area. Section 2.3 then summarizes the existing evidence for the potential impact of poverty on cognitive function and economic behavior via various channels, including malnutrition, alcohol consumption, monetary concerns, physical pain, sleep deprivation, environmental factors, stress, and depression. Section 2.4 shifts focus to the impact of different areas of cognitive function on economic outcomes, and more broadly to future income, wealth, decision-making, and poverty. Finally, section 2.5 concludes by highlighting open questions and high-value areas of future research in the relationship between cognitive function and poverty. 


\subsection{Cognitive Functions}

This section begins with a brief overview of cognitive functions crucial to economic outcomes and decision-making. Following this overview we will discuss four key aspects of cognitive function in detail, as well as canonical tests to measure them. Additional detail on the cognitive functions we consider here can be found in Lyon and Krasnegor (1996), Suchy (2009), and Diamond (2013).

\subsubsection{Overview of Cognitive Functions}

The brain and its many functions have been studied by researchers in psychology, neuroscience, and other fields for many decades. Each of its roles - for example, movement, sensory input, and interpretation - is essential to daily life. There is, however, one set of functional areas that is of particular relevance and interest to decision-making and economic life. Termed "cognitive function" or "executive function" in the cognitive psychology literature, these are broadly defined as mental processes that control one's attention, dictate one's ability to work with information, and are required for deliberate activity. Cognitive functions are crucial to task performance and decision-making, and carry longer-term impacts such as literacy and school performance (Borella, Carretti, and Pelegrina 2010; Duncan et al. 2007).

Cognitive functions are top-down processes, initiated from the prefrontal cortex of the brain, that are required for deliberate thought processes such as forming goals, planning ahead, carrying out a goal-directed plan, and performing effectively (Lezak 1983; Miller and Cohen 2001). Although most researchers agree on this general understanding of cognitive functions, there is a wide array of views on details such as how to categorize its subcomponents, which neurological brain circuits are required for different areas of functioning, and whether there exists one unifying mechanism underlying all cognitive functions, also known as the "Theory of Unity" (Kimberg et al. 1997; de Frias, Dixon, and Strauss 2006; Godefroy et al. 1999; Jurado and Rosselli 2007).

Although beliefs are wide-ranging, most researchers would agree that there is no one unifying mechanism, and broad classification of subcomponents is possible (Miyake et al. 2000). In this chapter, we will utilize this classification system of subcomponents of functioning, focusing on four aspects of cognitive functions that are both generally agreed upon by cognitive psychologists and that we consider central to understanding economic behavior and outcomes. This list is not fully exhaustive, and the complexity of and overlap in cognitive functions make many categorizations possible, especially for higher-order functions. However, in order to keep this introduction to the topic a tractable reference, we focus on a limited number of subcomponents with stronger agreement in their categorization and direct relevance to economic choices. 
I. Attention is the ability to focus on particular pieces of information by engaging in a selection process that allows for further processing of incoming stimuli. This process can happen voluntarily or involuntarily. For instance, attention alerts us to sudden loud noises (involuntarily) or enables us to comprehend a bullet point on a presentation slide (voluntarily).

II. Inhibitory Control is the ability to control impulses and minimize interference from irrelevant stimuli. It is used to block out distractions, to control impulsive urges, and to override prepotent responses. For example, an application of inhibitory control is stopping yourself from reaching for a chocolate cookie on the table when you are exhausted after a long day.

III. Memory is the ability to recall, recognize, and utilize previously learned information. Of particular interest in this chapter is working memory, the ability to evaluate new information as it enters, to manipulate the information if necessary, and to delete or update irrelevant existing information. For example, the use of working memory enables us to remember a conversation with another conference attendee, and then to revisit the topic later and update a draft paper.

IV. Higher-Order Cognitive Functions involve one or more of the basic cognitive functions highlighted above and are therefore considered more complex. This chapter will discuss three higher-order cognitive functions: cognitive flexibility, intelligence, and planning.

Cognitive flexibility is a higher-order ability that involves switching between tasks, rules, or mental sets (Lezak, Howieson, and Loring 2004). For example, if a small business owner decides to implement a new bookkeeping system, adjusting to this change requires a combination of inhibiting existing habits, attending to the old and new rules, and actively adopting the new system - a more involved process compared to one that merely relies on a single cognitive function. Cognitive flexibility is also used interpersonally, helping us to understand others' perspectives in situations of potential conflict.

Intelligence is commonly separated into fluid and crystallized intelligence. The former refers to the ability to solve novel problems and the latter involves the ability to use learned languages, subjects, skills, and so forth. Both forms of intelligence involve a combination of core functions such as attention and memory, rendering them "higher order," that is, more complex cognitive functions (Cattell and Horn 1966).

Planning - also sometimes known as "sequencing" - is the ability to generate a strategy, including the sequencing of steps, which meets intended goal(s). This function is central to many economic activities. For example, just to open for the day, the manager of a restaurant must anticipate demand, contract with the necessary suppliers, and organize staff schedules-all tasks that involve sequencing steps appropriately to meet an intended goal. 
Each of these broad constructs has the potential to help shape our understanding of the relationship between poverty, decision-making, and productivity. Each has direct relevance to a variety of types of economic decision-making, as well as the potential to be shaped by poverty and its correlates. Such effects, if large enough, may in turn lead to reduced socioeconomic mobility or potentially even poverty traps. Before discussing the potential relationship between these areas of cognitive function and economic outcomes, we provide a more thorough description of each area of cognitive function, as well as examples of ways to measure them, in order to facilitate their integration into economic studies. Appendix table $2 \mathrm{~A} .1$ provides a summary of tasks that can be used to measure cognitive function, including some of their advantages and disadvantages for use in development economics.

\subsubsection{Attention}

\section{Definition and Description of Attention}

Given its fundamental nature underlying several other cognitive functions and its relevance to decision-making, attention has garnered exceptional interest among both psychologists and economists (Pashler 1998). This interest has generated a wide-ranging and deep literature in psychology, with many active debates and disagreements about the precise definition, role, and boundaries of attention. This chapter aims to define attention in a manner consistent with the prevailing views in cognitive psychology, while noting some of the most substantial disagreements with that view. Notably, we focus only on conscious attention for the purposes of this chapter, as opposed to aspects of attention, such as priming, that could happen subconsciously.

At its most basic level, attention is the selection of information for further processing. A key feature of attention is that it is limited (Broadbent 1958). It is not possible to attend to and encode the millions of stimuli encountered each day. That is, attention filters information into or out of processing mechanisms, enabling us to focus more effectively on the things we care about (Sternberg and Sternberg 2011; Treisman and Gelade 1980; Cohen 2014). Given this filtering role, and because one usually attends to a stimulus before being able to retain or recall information, the early and still prevailing view is that attention is a key component of memory (Yates 1966; Phelps 2006).

Within the realm of attention, researchers have made significant headway in understanding the mechanisms underlying attention by separating it into categorical types:

Internal versus External Attention. One such categorical distinction is the separation between internal and external attention (Chun, Golomb, and Turk-Browne 2011). Internal attention is the selection, modulation, and maintenance of internally generated information. For instance, a use of internal attention would be thinking about the upcoming deadline for a 
journal submission. In contrast, external attention is the selection and modulation of incoming stimuli from your surroundings, for example, viewing images as they appear on a television screen.

Narrow versus Broad Attention. A second categorical distinction of attention is narrow versus broad attention (Wachtel 1976). In broad attention, a person pays attention to many stimuli or attributes of stimuli simultaneously, whereas in narrow attention, the person excludes irrelevant information, allowing for a limited focus. This categorization of attention is considered to coexist with internal and external attention. The theory of attention developed by Nideffer (1976), and the scale developed from it (the Test of Attention and Interpersonal Style), states that attention is a two-factor process, measured by both breadth (narrow versus broad) and direction (internal versus external), and that people use combinations of these two factors of attention depending on the task at hand. For instance, a student solving a math problem on an exam would be using narrow internal attention, whereas that same student would use broad external attention when arriving at a party later that night to scan the room, see who is present, and decide who to begin talking to.

Simple versus Complex Attention. Related to narrow versus broad attention, but less well known, is the classification of simple versus complex attention, as proposed by Lim and Dinges (2010). Simple attention refers to attending to one stimulus, whereas complex attention refers to attending to multiple stimuli at the same time. While this categorization is not very common among psychologists, tasks devised to measure cognitive functions can be to a large extent related to either simple or complex attention. As such, this categorization provides a straightforward structure to understand attention and, in particular, to study the potential relationship between poverty and cognitive function.

Other classifications are arguably less informative when considering downstream effects such as economic decision-making and productivity. For example, posterior and anterior attention studied in neuroscience focus on the specific neurotransmitters that are active in the brain when attending to different stimuli and investigate in depth the particular brain cells at play (Peterson and Posner 2012). Due to our focus on the relationship between cognitive function and economic outcomes of interest, these discoveries are not our primary focus; therefore, we proceed with the simple versus complex attention categorization. The next section provides examples of tests measuring simple and complex attention.

\section{Measuring Attention}

One of the areas of attention with potentially significant consequences to human behavior is "sustained attention," also commonly referred to as "vigilance" or "attentional vigilance" (Egeland, Johansen, and Ueland 2009). This skill is the general ability to detect a stimulus during times of 
habituation and/or tiredness (Mackworth 1968; Robertson et al. 1997). A common example of this skill is driving, especially while fatigued. In lab and field settings, measuring vigilance usually involves identifying a target signal from a pool of otherwise continuous and repetitive nontarget stimuli. This section describes canonical tasks used to measure this skill, in both its simple and complex forms.

I. Psychomotor Vigilance Task. Within simple attention, one widely used task to measure attentional vigilance is the Psychomotor Vigilance Task (PVT). The PVT is especially popular among sleep researchers (Basner and Dinges 2011; Basner, Mollicone, and Dinges 2011; Dinges et al. 1997). In this task, researchers ask participants to press a button when a stimulus, such as a light or a colored dot, appears. The task measures reaction time and accuracy - in other words, how quickly the participant (correctly) presses the button when the stimulus appears, and how often she presses the button when no stimulus appears (a false response). In a review by Basner and Dinges (2011), the most common outcome metric of the PVT is the number of "lapses," reported by around two-thirds of published studies. Lapses are usually defined as a reaction time of longer than 500 milliseconds and are understood as breaks in one's attention (Lim and Dinges 2008). Other commonly used metrics are mean reaction time, inverse reaction time, fastest 10 percent of reaction times, and median reaction time. The PVT collects extremely granular data, as it is administered on a computer (or other electronic device) and records time on a millisecond scale. Researchers can easily adjust factors such as interstimulus interval - the time and regularity of gaps between the appearance of two stimuli, a feature that impacts task difficulty. Participants exhibit limited learning effects in this task, making it ideal for repeated use in within-subject designs (Dorrian, Rogers, and Dinges 2005). The task does, however, require electronic administration, which can make it inconvenient in certain field settings. Increasing the duration of the task generally increases error rates, especially when implemented along with a battery of other cognitive tasks (Lim et al. 2010).

II. Concentration Endurance Test. In contrast to simple attention tasks, complex attention tasks involve more than one stimulus and/or more than one rule. The Concentration Endurance Test, also known as the "d2 Test of Attention," is a task that aims to measure sustained attention (Bates and Lemay 2004). Participants view a continuous list of letters $p$ and $d$, with up to two marks above and up to two marks below each of the letters. The participants then identify and cross out each case of the letter $d$ that has two associated marks. Common outcome variables include the total number of correct cancellations, errors, and the distribution of errors. The task requires participants to recognize the letter "d," making literate participants more easily able to complete the task, but it can be administered using similar shapes as opposed to letters for nonliterate participants or participants whose native language does not use the Latin alphabet. Notably, the task requires accurate 
visual scanning, which can be impeded not only by poor attention, but also by poor eyesight, a common concern in developing countries.

\subsubsection{Inhibitory Control}

\section{Definition and Description of Inhibitory Control}

Inhibitory control is a top-down mental process that blocks out distractions, controls impulsive urges, and overrides prepotent responses (Rothbart and Posner 1985). It is sometimes used interchangeably with self-control, and is also referred to as "selective attention," "attentional control," "attentional inhibition," and "executive attention" (Lavie et al. 2004; Kane and Engle 2002; Kaplan and Berman 2010). The ability to control impulses has been studied extensively in child development (Carlson and Moses 2001; Diamond and Taylor 1996; Mischel, Shoda, and Rodriguez 1989) as well as among adults (Ward and Mann 2000; Dempster 1992). This important aspect of cognitive functioning enables people to perform well socially, physically, at work, and in society. For example, discipline and self-control are required to refrain from eating when on a diet (Shiv and Fedorikhin 1999), or to inhibit socially inappropriate responses when mentally drained (von Hippel and Gonsalkorale 2005).

One notable model of self-control proposes that self-control is governed by a limited resource that can be depleted over time (Baumeister et al. 1998; Muraven, Tice, and Baumeister 1998). This model, known as the "egodepletion" model, has been empirically tested, with meta-analyses finding small effect sizes. But more recent replications of the task used to study this phenomena have called this conclusion into question, with a preregistered trial involving twenty-three labs and over 2,000 participants finding no significant effect (Hagger et al. 2016).

However, there is better evidence that situational factors can have a significant effect on self-control. In addition to individual differences, variable factors in one's environment or life circumstances such as fatigue or cognitive load may also affect the availability of this limited mental resource (Inzlicht and Schmeichel 2012; Muraven and Baumeister 2000). For example, it is much more difficult to suppress one's impulses after exposure to stress (Glass, Singer, and Friedman 1969) or when working in a crowded space (Sherrod 1974), both prevalent conditions faced by the urban poor. Empirically, recent prominent work on self-control has focused on exploring the consequences of depleted self-control and ways to overcome this depletion (Baumeister 2002; Hofmann, Rauch, and Gawronski 2007; Hofmann, Friese, and Strack 2009).

\section{Measuring Inhibitory Control}

This section describes a subset of the many cognitive tasks used to measure inhibitory control. Researchers have applied the tests discussed below 
in a wide range of settings and populations, providing a useful guide for designing future experimental studies related to inhibitory control.

I. Hearts and Flowers Task. This task, previously known as the Dots Task, shows participants a screen that is divided into two panels where either a heart or a flower appears on one side of the screen. ${ }^{1}$ In the first round, participants are shown only hearts and are asked to click a button on the same side as the heart whenever it appears. In the second round, only flowers appear and participants are asked to click on the opposite side of the screen as the flower. Finally, in the third round, individuals see both hearts and flowers, and the goal is to click on the appropriate side of the screen according to the rule for each stimulus. Round 2 and in particular round 3 measure inhibitory control, as they require individuals to override their natural tendency to press on the same side whenever flowers appear on the screen. While this test does require inhibitory control, it has been critiqued as also requiring working memory (Diamond 2013). A different version of this test, using arrows instead of symbols, is particularly effective at separating inhibitory control from other cognitive functions (Davidson et al. 2006). ${ }^{2}$ The test can be made more difficult by decreasing the amount of time individual stimuli appear on the screen. Though this task is most effectively administered electronically, it is well suited for economic development research. It is quick, easy to explain, and does not require specific background knowledge or a specific education level, making it applicable in a wide range of settings.

II. Eriksen Flanker Task. In this task, participants are shown a set of five stimuli, of which they are supposed to respond only to the middle stimulus (Eriksen and Eriksen 1974; Mullane et al. 2009). A common version of this task uses an arrow as the target (middle) stimulus. Respondents have two buttons - one left and one right - and are asked to press the button corresponding to the direction of the target arrow. The target stimulus can be flanked by congruent stimuli (e.g., arrows pointing in the same direction as the target), incongruent stimuli (e.g., arrows pointing in the opposite direction of the target), or neutral stimuli (e.g., squares flanking the target arrow). Incongruent stimuli require participants to use top-down control to focus on the middle stimulus (Diamond 2013). Using an arrow as the stimulus for this task minimizes memory requirements from participants, as the arrows indicate where the participant is supposed to respond. This task is best performed electronically, and researchers have limited ability to manipulate its difficulty. When conducted using arrows as described above, however, the test does not require any background knowledge or educational attainment

1. The Hearts and Flowers Task is quite similar to an older task known as the Simon task. This task has two rules: press left for one stimulus, and press right for a second stimulus. The stimulus can appear on the right or left side of the screen. While the side of the screen on which the stimuli appear is irrelevant, respondents tend to be quicker when the stimuli appear on the same side as their associated response (this is termed the Simon effect) (Lu and Proctor 1995).

2. As it only requires participants to hold one rule in mind at a time it does not require working memory. 
level, and more effectively separates inhibitory control from other cognitive functions such as working memory.

III. Stroop Test. While there are a number of versions of the Stroop Test, we detail two in this chapter: the Classic Stroop Test and the Spatial Stroop Test.

The Classic Stroop Test displays a list of words that spell out the names of colors (Stroop 1935). The congruent condition occurs when the word matches the ink color (e.g., the word "blue" is displayed in blue ink). Conversely, the incongruent condition occurs when the word is displayed in a different color ink (e.g., the word "blue" displayed in green ink). The goal of the task is to name the color of the ink as opposed to the word, for instance, blue in the congruent condition and green in the incongruent condition (MacLeod 1991). ${ }^{3}$ Although it is a common test in developed countries, the Stroop Test has several disadvantages for development researchers. In particular, most versions require literacy, and different educational levels are likely to affect performances. A numeric version of the task can overcome the literacy barrier, although it may still be problematic if numeracy is also low. The test is also typically conducted electronically (though it can be done with paper and a stopwatch), and there is little researchers can do to manipulate its difficulty other than shorten the response time.

The Spatial Stroop Test relies on the same basic concept as the Classic Stroop Test, but measures spatial rather than verbal and visual incompatibility. Researchers show participants both relevant and irrelevant dimensions of a stimulus, which are similar and can influence responses. For example, in one variant, participants are shown an arrow that points left or right (in another variant they are shown the words "LEFT" or "RIGHT") and that is displayed on either the left or right side of the computer screen. Participants are asked to press the button on the side the arrow is pointing to, ignoring the location of the arrow on the computer screen. While the side of the screen on which the stimuli appear is irrelevant, respondents tend to be quicker when the stimuli appear on the same side as their associated response. This version of the task has an advantage over the Classic Stroop Test in that it does not require literacy when using the arrow stimuli. Though generally administered electronically, this task is otherwise well suited to field settings, as it is both quick and easy to explain. Researchers can also alter the difficulty of the task easily by adjusting its speed.

\subsubsection{Memory}

\section{Definition and Description of Memory}

Memory is the ability to encode, store, retain, and retrieve information and previous experiences (Kandel, Schwartz, and Jessell 2000). This ability

3. Although the classic Stroop Test is a prototypical test of inhibitory control (Miyake et al. 2000), MacLeod et al. (2003) argue that the "Stroop effect" or "Stroop interference"-a delayed response when ink color differs from that of the displayed word - may not measure inhibition. 
to retain and use previous knowledge supports relationship building and is essential to learning. Memory has multiple components; for instance, auditory memory is the ability to process and retain oral information (information given "out loud"), whereas visual memory is the ability to remember what one has seen. Short-term memory describes the brain's ability to retain information for a short amount of time. Information can then be stored for long-term usage via rehearsal or active processing. Closely connected to short-term memory is working memory, which describes a person's ability to simultaneously store and manipulate (work with) information. More information on short-term, long-term, and working memory follows.

Short-Term Memory and Long-Term Memory. Research on memory has explored the relationship and interactions between what we commonly and intuitively refer to as "short-term memory" and "long-term memory" (James 1890). Short-term memory is defined as information that enters into conscious memory through a sensory registry such as through the eyes or sense of touch. Information then resides for a short period of time in the conscious memory but will be forgotten if not deliberately rehearsed or managed. Scientists generally agree that the capacity of short-term memory is limited, with seven plus or minus two considered to be the typical number of items one can hold in short-term memory at the same time (Miller 1956). Following extensive rehearsal and active processing, information solidifies and moves into long-term memory, where it is retained for future use. When people's actions, decisions, and speech require them to retrieve information from long-term memory, the memory or information moves back into short-term memory for active use. Compared with the limited capacity in the short-term store, researchers hypothesize that the capacity of the long-term store is unlimited (Cowan 2008).

Working Memory. Research in recent decades has largely replaced the concept of short-term memory with an integrated, multicomponent classification known as working memory (Baddeley and Hitch 1974). Working memory refers to the set of cognitive processes involved in the temporary storage and manipulation of information (Diamond 2013). For example, a waitress taking orders at a dining table could use working memory to remember all the orders without writing anything down. She might also manipulate the "data" in her mind by grouping all the appetizers, all the drink orders, and so on. This combination of temporary storage and manipulation is the core of working memory. As with short-term memory capacity, individuals' working memory capacity is limited. There is some disagreement among researchers in psychology about how working memory fits into the broader category of cognitive function. In particular, working memory and inhibitory control are often difficult to parse completely. One possibility, which is popular within computational modeling, is to group inhibitory control with working memory (Hasher and Zacks 1998, 2006; Miller and Cohen 2001; Munakata et al. 2011). However, although there is some overlap, here 
we treat working memory and inhibitory control as distinct due to their differential impacts on economic outcomes, as we will outline in section 2.4.

\section{Measuring Memory}

Cognitive psychologists have devised numerous tasks to measure shortterm and working memory. We discuss four such tasks, including their relevant variations.

I. Digit Span Tasks. To measure short-term memory, researchers often use the Forward Digit Span Task, in which participants are read a list of numbers and then asked to repeat these numbers in the same order (Daneman and Carpenter 1980,1983). Participants with a lower level of numeracy may be at a disadvantage in this task, so researchers can substitute simple items or words in place of numbers as needed. One also can modify this task to have participants listen to and repeat nonnumerical items and reorganize them. For instance, modifications might include providing participants with a series of letters to list back in alphabetical order (requires literacy) or a series of objects to list back in order of size (requires background knowledge of items, which may differ across settings). This task is easy to implement in the field - it does not require any equipment other than what is needed to record participants' responses. Outcomes for this study are accuracy and the longest correctly remembered span. It is easy to make this test more challenging by increasing the number of digits or objects the participants are asked to remember. Closely related to the Forward Digit Span Task is the Reverse Digit Span Task. Intuitively, the task asks participants to listen to a list of numbers and repeat them in reverse order. Similar to the modifications of the task discussed above, this version of the task is commonly used as a measure of working memory because it requires some manipulation of information instead of mere repetition. This task has the same implementation challenges as the Forward Digit Span Task, but similar modifications can be implemented. Both the forward and reverse digit span tasks are sometimes implemented asking the participant to reorder the digits numerically. However, this version of the task is less desirable in contexts where numeracy is low.

II. Corsi Block Test. The Corsi Block Test (Corsi 1972) is well suited to measure visual-spatial memory (Lezak 1983). Participants view a series of spatially separated blocks, which individually change colors in a random sequence. They then tap or click the series of blocks in the order in which they changed color. In an alternative version of this task, a researcher will tap individual blocks and participants are then asked to tap these blocks in the same order as the researcher. The sequence typically starts out with a small number of blocks (e.g., each series will consist of two flashing blocks) and then becomes more and more difficult as the number of blocks in the series increases. As initially designed, the Corsi Block Test does not require mental manipulation, which categorizes it as a short-term memory test rather than a working memory test. However, the Reverse Corsi Block Test, 
in which participants reverse the order of the indicated blocks, measures working memory. The Corsi Block Test is also relatively easy to implement in the field; it can be administered on paper or electronically, and a tablet version, eCorsi, has been developed (Brunetti, Del Gatto, and Delogu 2014). The task also does not require any particular background (such as numeracy), making it particularly well suited for research in development economics. Furthermore, researchers can easily increase the test's difficulty by increasing the number of blocks respondents must remember.

III. N-Back Task. The N-Back Task is a commonly used test of working memory. In this task, participants are presented with a series of stimuli. They are then asked to press a button or otherwise indicate if the current stimuli matches the stimuli presented $n$ stimuli prior (Kirchner 1958). Both accuracy and speed are measured as outcomes of interest. This task can take a visual form, in which a series of objects are shown on a screen, or an auditory form, where a participant listens to a series of words. A third variant of the task, the "dual-task" version, uses a similar framework but presents two independent, simultaneous sequences - typically one visual and one auditory, to which respondents must respond (Jaeggi et al. 2003). While N-Back is widely used, its validity as a test of working memory has been questioned by studies finding that its results are only weakly correlated with other well-accepted measures of working memory (Jaeggi et al. 2010; Kane et al. 2007). In its general form, the test generally does not require literacy or numeracy, unless words, letters, or numbers are used as stimuli. It can be made more or less difficult by adjusting the $n$ parameter or speed of the stimuli.

IV. Self-Ordered Pointing Task. This test measures nonspatial or spatial working memory (Petrides et al. 1993; Petrides and Milner 1982). Participants are shown three to twelve objects (in the form of boxes with line drawings or other identifiable stimuli), and are then asked to touch one item at a time, without repeating items, until each object has been touched. However, the test randomly scrambles the locations of the objects in between turns. A modification of this task that measures spatial working memory also includes an identical set of objects that remain stationary throughout the task (Diamond et al. 2007; Wiebe, Lukowski, and Bauer 2010). One can manipulate the difficulty by increasing the number of items. The task can be carried out either electronically or using physical objects (or paper drawings). It does not require participants to have a specific background or a certain level of education, making it appropriate in a wide range of settings.

\subsubsection{Higher-Order Cognitive Functions}

\section{Definition and Description of Higher-Order Cognitive Functions}

In the previous sections we presented attention, inhibitory control, and memory as unidimensional cognitive functions because researchers attempting to understand the human mind typically focus on one specific aspect of 
functioning while controlling for or mitigating the influence of unrelated areas in order to obtain the cleanest results. However, as described previously, attention, inhibitory control, and memory are all interrelated and difficult to fully disentangle because they utilize the same region in the brain (Stuss and Alexander 2000). ${ }^{4}$

In fact, real-life human behavior rarely relies on one cognitive domain alone and instead usually requires a combination of these underlying functions. For example, think about the seemingly simple act of crossing a road. All of the core cognitive functions are at play here. First, you pay attention to the traffic light and the passing vehicles. Looking at the cars, you use working memory to calculate their speed and distance and contemplate whether jaywalking seems safe enough. However, you decide to suppress your impulse to jaywalk because the young child next to you is patiently waiting for the green light and you want to set a good example; you exert inhibitory control. This example illustrates the complexity involved in almost every decision or action we take, even those that appear mundane on the surface. Instead of using a unidimensional cognitive function, our actions and decisions typically require a multidimensional approach, combining several of the cognitive functions discussed so far. In this section, we discuss the more advanced types of cognitive functions, which we refer to as "higher-order cognitive functions," focusing on cognitive flexibility, intelligence, and planning, three key areas with the potential to greatly impact economic outcomes.

Cognitive Flexibility. The ability to adapt to changing circumstances is referred to as cognitive flexibility (Friedman et al. 2006; Andrewes 2001). This mental process is used when a situation is altered and there is a need to adapt to the new context by updating procedures to reflect new circumstances, rules, or environments. Cognitive psychologists hypothesize that cognitive flexibility is composed of three steps (Martin and Rubin 1995; Martin and Anderson 1998). The first is an awareness that there are options and alternatives available in a given situation. The second is a willingness to be flexible and adapt to a given situation. The third is the decision to make the switch and modify behavior or beliefs given the situation. Researchers argue that all three steps are critical because one cannot adapt to a new rule without an awareness of it, and similarly, one would not successfully adapt to the new rule without the willingness and ability to change. Cognitive flexibility is also referred to as set shifting, task or attention switching/ shifting, cognitive shifting, and mental flexibility (Tchanturia et al. 2012; Canas et al. 2002).

Fluid and Crystallized Intelligence. General intelligence is typically considered to have two components: fluid intelligence and crystallized intelligence (Horn and Cattell 1967). Fluid intelligence refers to the ability to

4. Diamond (2013, figure 4) is an excellent summary of the interrelation of cognitive functions. 
solve novel problems and to adapt to new situations. Frequently abbreviated as $g F$ in the literature, researchers believe fluid intelligence exists independently of acquired skills and knowledge (Cattell 1963). Individuals who use logic such as deductive reasoning to solve a puzzle or think about problems abstractly employ fluid intelligence. As a higher-order cognitive function, it is most often associated with memory, in particular, working memory, which involves updating and manipulating information. In contrast, crystallized intelligence, commonly abbreviated as $\mathrm{gC}$, relies on acquired skills and knowledge from one's schooling and/or upbringing. Crystallized intelligence can be formed from experience or information and also relies on memory, in particular, long-term memory (Knox 1997). Notably, intelligence measures are often used interchangeably with other decision-making activities. For example, many researchers view reasoning and problem solving as synonymous with fluid intelligence (Diamond 2013); others group reasoning and crystallized intelligence together as a closely related construct (Lim and Dinges 2010).

Planning is a higher-order construct that captures the ability to think strategically about how best to sequence steps in order to obtain a goal. In order to plan well, individuals must consider multiple hypothetical sequences of events and actions that could be used to reach an intended outcome and then assess which will most efficiently and effectively help them reach the intended outcome (Carlin et al. 2000). This construct is also sometimes referred to as "sequencing." There is less direct agreement on how to categorize and define planning given the large number of underlying aspects of cognitive function required, including some higher-order functions, but its direct relevance to economic choices and actions make it worthwhile to consider nonetheless (Miyake et al. 2000; Beshears, Milkman, and Schwartzstein 2016). In the context of this chapter-considering both psychological approaches and economic approaches - it is important to note that there is a key distinction between the ability to plan and the act of undertaking planning. The psychological approach to planning focuses more on planning ability. We will follow this approach here as a useful first step. However, the economic approach to planning would also want to consider whether an individual chooses to make a plan and follow through on it. Since those choices also draw on other domains, we will limit our discussion to measuring planning ability for the purposes of this chapter.

\section{Measuring Higher-Order Cognitive Functions}

This section describes tasks used to measure higher-order cognitive functions. We divide the tests into four categories: (a) cognitive flexibility, (b) fluid intelligence, (c) crystallized intelligence, and (d) planning.

I. Wisconsin Card Sorting Task. Measuring cognitive flexibility often involves a series of set-shifting tasks. A prominent example is the Wisconsin Card Sort Task, in which participants are provided with a deck of cards, 
each of which can be sorted by color, shape, or number (Berg 1948; Grant and Berg 1948). The objective here is for participants to learn the correct sorting criterion based on feedback provided by the experimenter as to whether they have sorted the card correctly. In this task, however, the rules change periodically and without notification, such that participants must learn to change the sorting rule based on the feedback they receive, which requires cognitive flexibility. In its standard form, the task requires the ability to read and understand numbers. However, it can be adjusted to only include color and shape. ${ }^{5}$ On the other hand, it is easy to explain and can be conducted electronically or with paper cards, making it practical in field settings.

II. Raven's (Progressive) Matrices Test. The most common and universally accepted measure of fluid intelligence (and a frequent component of IQ tests) is the Raven's Matrices Test, developed by the British psychologist John Raven almost eighty years ago (Raven 1936, 2000). In this test, researchers ask participants to consider a main figure that is missing a section. The goal of the task is to choose the missing piece that will complete the figure with a logical pattern from a set of (typically eight) options. Easier versions of Raven's Matrices involve simple matching tasks such as identifying the shape that matches the other shapes in the figure, while more difficult puzzles require participants to solve an analytical problem or apply multiple logical rules (Prabhakaran et al. 1997). While the traditional Raven's Matrices set contains sixty such trials, more recent studies that use this task as part of a larger battery of tests use fewer trials (Mani et al. 2013; Raven 2000). Researchers can alter the difficulty of a Raven's Matrices task by increasing the number of multiple choice options available or the complexity of the rules participants must deduce to complete the puzzle.

III. Wechsler Adult Intelligence Scale (WAIS). Researchers frequently use this test to measure both fluid and crystallized intelligence. Composed of eleven subtests, the WAIS consists of both a "verbal" and a "performance" component (Lichtenberger and Kaufman 2009; Wechsler 2008). The verbal sections include vocabulary, digit span, comprehension, and arithmetic. The performance sections include picture completion and arrangement, object assembly, and so forth. There are three variants of Wechsler Intelligence Tests, designed for (a) adults, (b) young children, and (c) older children, each of varying difficulty. As described above, tasks that measure crystallized intelligence rely on previous knowledge. As a result, performance on subtests that involve vocabulary or sentence completion can be limited by language skills, making implementation and interpretation difficult in many developing-country settings. The test has been translated into over twenty languages to date.

5. See, for instance, "Berg's Card Sorting Test," the Psychology Experiment Building Language (PEBL) computerized version of the Wisconsin Card Sorting Task. 
IV. Tower of London Task. The Tower of London Task is among the most common tasks used to measure planning ability. In this task, participants are presented with two configurations of three stacks of small colored disks arranged on pegs. The first configuration of the disks is the target or goal arrangement and the second configuration of the disks is the starting arrangement. The participant's task is to reach the goal arrangement from the starting arrangement in the fewest possible moves of disks (Banich 2009). To complete the task by moving the disks from the starting arrangement to the goal arrangement, participants must follow a number of different rules. The specifics of the rules may vary to alter the difficulty of the task, but typically fall into three categories: (a) the number of disks that can be moved at one time - typically just one disk can be moved at a time; (b) which disks can be moved - typically only the top disk in the stack; and (c) limits on the number of disks that can be placed on a single peg-typically either the same across all pegs or descending with the height of the peg (e.g., three disks on the tallest peg, two on the peg of intermediate height, and only one on the shortest peg).

As the goal of the task is to capture planning ability, the participants are asked to plan ahead mentally before carrying out the task physically. Participants typically undertake a large (e.g., twenty) number of trials of varied difficulty to more precisely capture the individual's ability. The complexity of the task can be increased by (a) increasing the number of colored disks used in the trial or (b) increasing the required number of moves to correctly complete the puzzle with a fixed number of disks. Outcome measures include the total number of moves, the number of trials solved in the fewest possible moves (considered to be "correct"), the time taken to plan in advance of starting to move the disks, and time taken to move the disks (Unterrainer et al. 2004).

\subsubsection{Practical Concerns}

Most of the tasks described above exhibit several useful features that promote ready utilization across a variety of domains. These features include ease of administration, broad applicability, and ease of instruction, as described in more detail in Schilbach, Schofield, and Mullainathan (2016). Yet, important caveats remain in order to successfully integrate these tasks into randomized trials or surveys. First among these is the importance of careful piloting of the task in the relevant population. As described above, there are often a variety of ways to adjust the difficulty of each task and piloting provides the opportunity to make appropriate adjustments for the population of interest. Selection of the task settings that are most appropriate for the context will help the researcher to avoid both floor and ceiling effects. In addition, integrating at least one and sometimes several practice rounds before starting the actual posttreatment trials to be used as outcome measures will reduce the variance unrelated to the treatment across par- 
ticipants. Piloting the task is typically necessary to identify the appropriate number of practice rounds to provide accurate measures and ensure comprehension of the task. Finally, piloting also provides an opportunity to fine-tune instructions in the local language and ensure that surveyors are providing complete and accurate instruction both via direct observation and via analysis of pilot data for variation in performance by the surveyor conducting the test.

Another important consideration in utilizing these tasks is the selection of appropriate outcome measures. In contexts with repeated measurement, participants increase proficiency, potentially leading to a significant fraction of participants reaching the maximal performance. This issue is particularly likely to arise for measures with a natural maximum (e.g., accuracy rates). It is possible to avoid this concern by considering measures without a natural maximum and with greater potential variation, such as reaction times. Some researchers have also used even more granular measurements of speed and accuracy, such as fastest 10 percent reaction times (Basner and Dinges 2011). Alternatively, another approach that can be effective in avoiding such concerns is to design the task to include multiple rounds of increasing difficulty.

\subsubsection{Identifying Alternative Tasks}

The tasks described here provide merely an overview of a few potential tasks that can be used to capture different elements of cognitive function. Many other tasks can also be used to measure these (and other) aspects of cognitive functions but were omitted for brevity. A number of websites provide resources to implement additional tasks, though they vary in the areas of cognitive functions targeted, as well as in flexibility and quality of implementation, instructions, and outcome data. A few such examples are provided below. In addition, although not yet finalized, the authors will post software and instructions for a number of the tasks described above to their websites shortly. This software is free of charge and is intended specifically for use in research, with flexible settings and comprehensive data collection.

Additional Resources for Cognitive Tasks:

1. ICAR: http://icar-project.org/. See also: http://icar-project.org/papers /ICAR2014.pdf.

2. Kikolabs: https://www.kikolabs.com/.

3. Cognitive Fun!: cogfun.net.

\subsection{Impact of Poverty on Cognition and Economic Behavior}

Although it may seem counterintuitive that a person's fundamental cognitive "capacity" can be altered by his or her circumstances, there is a small but growing literature that demonstrates poverty can and does impact cognitive function in a variety of ways. This section briefly discusses some of the 
factors associated with poverty that have been shown to impact cognitive function and economic behaviors. Moreover, it provides a nonexhaustive introduction to other aspects of life in poverty for which the evidence is more limited but suggestive of potential negative impacts and warrant further investigation. For each of the factors described below, a growing body of evidence of its impact on cognitive function and economic behaviors exists. However, much more evidence is needed to fully understand such impacts. Moreover, we have only very limited evidence regarding individuals' awareness of these potential effects.

\subsubsection{Malnutrition}

Throughout history, malnutrition has been associated with poverty. This relationship is still present today. One-seventh of the world's population is below the level of caloric intake recommended by health professionals, and the vast majority of these individuals are among the poor in developing countries (Food and Agricultural Organization of the United Nations et al. 2011). Economists have studied this relationship for over sixty years, modeling nutrition as both consumption and an input into physical productivity (Leibenstein 1957; Bliss and Stern 1978; Stiglitz 1976; Dasgupta and Ray 1986). However, in recent years, the possibility of such traps has been discounted due to good evidence that liquidity is unlikely to constrain investment in calories. Hence, a revealed preference argument suggests that despite the apparently low consumption, any productivity gains from additional caloric intake are likely to be relatively small — less than the discount rate. Yet, there are both behavioral and structural reasons why this argument may not hold and, to date, a potentially critical aspect of this relationship may have been overlooked: too little food may impact not only physical function, but also mental function: thoughts may become lethargic, attention difficult to sustain, and temptations harder to resist (Fonseca-Azevedo and Herculano-Houzel 2012; Gailliot et al. 2007; Danziger, Levav, and Avnaim-Pesso 2011; Baumeister and Vohs 2007; US Army Institute of Environmental Medicine 1987).

Schofield (2014) tests this idea with a randomized trial that examines the impact of additional calories on measures of cognitive function among low-BMI cycle-rickshaw drivers in India over a five-week period. Study participants undertook a battery of both physical and cognitive tasks at the beginning and end of the study, in addition to reporting their labor supply and earnings daily throughout the study. The increased caloric intake improved not only labor market outcomes, but also cognitive outcomes; treated individuals showed a 12 percent improvement in performance on the laboratory-based cognitive tasks. This gain occurred almost immediately and was sustained at the fifth week. In addition, these changes also manifested in a real-world effort discounting task in which participants could choose to provide no labor and earn nothing, to take a journey with a lighter load today, or to take a journey with a heavier load tomorrow, with 
both trips earning the same payment tomorrow. In this decision, treated participants were 25 percent more likely to opt to take the journey today instead of delaying at the cost of a more difficult trip tomorrow, suggesting a meaningful reduction in discount rates for effort in their work.

\subsubsection{Excessive Alcohol Consumption}

Excessive alcohol consumption has been associated with poverty at least since Fisher (1930), yet the underlying causal channels of this relationship remain largely unknown. Some aspects of poverty such as physical or mental pain might increase individuals' demand for alcohol by enhancing its short-term benefits. However, poverty might also be caused or deepened by excessive alcohol consumption. By impeding mental and physical function, alcohol consumption might distort decision-making and lower productivity. More specifically, Steele and Josephs (1990) posit in their "alcohol myopia" theory that alcohol's narrowing effect on attention causes individuals to focus on simple, present, and salient cues, which may in turn lead to shortsighted behaviors.

In a three-week randomized field experiment in Chennai, India, Schilbach (2017) tests whether such cognitive effects can translate into economically meaningful real-world consequences. In this study, financial incentives reduced daytime drinking among low-income workers in Chennai, India. Higher sobriety due to the incentives caused a large increase in individuals' daily savings as measured by their daily deposits into a personal savings box at the study office. Since the incentives for sobriety caused only minor changes in alcohol expenditures and labor market earnings, the impact of increased sobriety on savings behavior appears to be due to changes in myopia rather than due to purely mechanical effects via increased income net of alcohol expenditures. Similarly, in a completely different context, Ben-David and Bos (2017) provide complementary evidence on the negative impact of alcohol availability on credit-market behavior in Sweden.

Many open questions regarding the role of alcohol consumption in the lives of the poor remain. First, much more work is needed to understand the causal impact of alcohol consumption on individuals and their families, including labor market behaviors, family resources, decision-making, violence, and well-being among women and children. Second, the underlying determinants of the demand for alcohol remain largely unknown. In particular, we do not know whether factors associated with poverty such as physical and mental pain, depression, or sleep deprivation contribute to the demand for alcohol. Third, little is known about the effectiveness of different interventions to curb undesired drinking in developing countries. Of particular interest could be the evaluation of government policies such as increased taxes or even prohibition on consumption of alcohol and its substitutes, as well as on potential downstream consequences of heavy drinking including poverty levels. 


\subsubsection{Physical Pain}

Heavy physical labor, uncomfortable living conditions, and limited access to adequate health care and pain-management tools all contribute to a disproportionate burden of physical pain in the lives of the world's poor (Poleshuck and Green 2008; Case and Deaton 2015). This inequality may be further compounded by disparate perceptions of pain; recent evidence suggests that economic insecurity in itself may increase perceived physical pain and lead to reduced pain tolerance (Chou, Parmar, and Galinsky 2016). Not surprisingly to those who have experienced physical pain, pain has been shown to negatively affect various cognitive domains including attention, learning, memory, speed of information processing, psychomotor ability, and capacity to self-regulate (Moriarty, McGuire, and Finn 2011; Nes, Roach, and Segerstrom 2009). Interference with one's thought process at inopportune moments can also make it difficult for individuals to focus, potentially competing for limited cognitive resources (Eccleston and Crombez 1999).

Such impacts on cognitive function have the potential to also affect economic decision-making, labor supply, and earnings. However, to date, few studies have investigated such effects. In one study, Kuhnen and Knutson (2005) found that people make more suboptimal financial decisions and are more risk averse after the anterior insula, the part of the brain that reacts to pain, is activated. Further, acute pain has been shown to increase shortsighted behavior as well as risk seeking when conditions involve potential gains (Koppel et al. 2017). Kilby (2015) considers the impact of changes in policies regarding prescription opioid pain relievers and finds increases in missed days for injured and disabled individuals. These studies underline the potential importance of a better understanding of the role of physical pain in the lives of the poor. However, much more evidence is needed to learn about the impact of physical pain on economic behavior and well-being among the poor as well as about potential policies to help individuals to alleviate their pain in a sustainable way.

\subsubsection{Sleep Deprivation}

While inadequate sleep is a widespread problem across the globe, the poor in particular may not sleep well (Patel et al. 2010; Centers for Disease Control 2015). Urban environments and developing countries are particularly prone to interfere with individuals' sleep due to the higher prevalence of ambient noise, heat, light, mosquitoes, stress, overcrowding, and overall uncomfortable physical conditions (Grandner et al. 2010; Patel et al. 2010). Moreover, suboptimal sleeping conditions may also hinder deep sleep, which is essential to cognitive functioning (Sadeh, Gruber, and Raviv 2002; Roehrs et al. 1994). Although not yet published, our data collected using small wristwatch-like actigraphs (which accurately measure sleep) worn by over 200 individuals for two weeks per person among the poor in Chennai, India, 
supports this idea. Individuals in our sample sleep just over five hours per night. This limited sleep may be further exacerbated by poor sleep quality, with more than twenty disruptions per night on average. Further, because the impacts of sleep deprivation increase with the cumulative extent of the deprivation, these impacts may be especially far-reaching among those with few options for "catching up" on sleep given poor sleep environments (Van Dongen, Mullington, and Dinges 2003; Basner et al. 2013).

A robust body of evidence demonstrates that sleep deprivation and lowquality sleep impair cognitive function, including reduction in attention and vigilance and impairments to memory and logical reasoning (Lim and Dinges 2010; Killgore 2010; Philibert 2005; Scott, McNaughton, and Polman 2006). Moreover, Baumeister and coauthors hypothesize that willpower is replenished overnight via sleep (Baumeister 2002). Similar to the literature on pain, much less work has been done to document the impact of these cognitive changes on economic decision-making and labor market outcomes. Notable exceptions include a series of papers by Dickinson and coauthors that demonstrate that acute sleep deprivation (such as a full night without sleep) has mixed effects on risk preferences (McKenna et al. 2007), reduces trust and trustworthiness (Dickinson and McElroy 2016), and reduces iterative reasoning in a $p$-beauty game in US populations (Dickinson and McElroy 2010). In addition, although the channels through which the effects operate are not explored, research utilizing shift work, shifts in sunset time, and child sleep quality as sources of quasi-exogenous variation in sleep find significant negative impacts of limited sleep on productivity (Gibson and Shrader 2015; Czeisler, Moore-Ede, and Coleman 1982; Costa-Font and Flëche 2017). However, much work remains to fully understand the productivity and decision-making consequences of sleep deprivation, particularly in developing-country contexts.

\subsubsection{Monetary Concerns}

One obvious consequence of being poor is having less money to buy things and improve one's environment. Less obviously, being poor also means having to spend more of one's cognitive resources managing what little money is available. The poor must manage sporadic income and constantly make difficult trade-offs between expenses. Even outside of financial decision-making, preoccupation with money and budgeting can act as a distraction, in effect taxing mental resources.

Mani et al. (2013) use two distinct but complementary research designs to establish the causal link between poverty and mental function. In the first study, the authors experimentally induce participants to think about everyday financial demands. For the rich participants, these thoughts are not worries. Yet for the poor, inducing these thoughts can trigger concern and distraction, with corresponding negative impacts on cognitive performance. Complementing this more "laboratory-style" study, the second study uses 
quasi-experimental variation in actual wealth over time among Indian farmers. Agricultural income is highly variable, with sugarcane farmers receiving income just once a year at harvest time. Because it is difficult to smooth their consumption across the year, these farmers experience cycles of povertypoorer before harvest and richer after - generating the opportunity to compare the cognitive capacity of a given individual across both "rich" and "poor" states (the authors rule out competing explanations, such as nutrition or work effort). Both studies produce consistent effects, with large and direct negative impacts of poverty on cognitive function; when living in poverty, economic challenges also manifest as cognitive challenges.

While the effects found in Mani et al. (2013) are striking, they are yet to be replicated in other settings. In fact, in the US context Carvalho, Meier, and Wang (2016) find no changes in cognitive function or decision-making around paydays among low-income workers using a pre-post design. For both studies, important identification concerns remain, which emphasizes the need for additional well-identified studies. Moreover, the existing work has not considered real-world economic behaviors. As a result, it remains an open question whether poverty impedes cognitive function in ways that translate into meaningfully large effects on economic outcomes such as labor supply, productivity, or savings behavior.

\subsubsection{Environmental Factors}

A variety of environmental factors including noise, heat, and air pollution may also tax cognitive function. These environmental irritants may have direct and indirect impacts on the poor, especially in the developing world and in particular in urban areas where exposure to these environmental irritants is often high (World Bank 2015). While we focus only on specific noise and air pollution below, other types of pollution, such as water contaminants, could also potentially have an impact on cognitive function and decision-making either through direct chemical channels or through other channels such "disgust."

Noise Pollution. In urban and developing environments, frequent noise pollution from car horns honking, dogs barking, or crowds chattering can make it difficult to focus and perform any given task at hand. Studies of noise levels in cities in developing countries have found noise levels significantly above World Health Organization (WHO)-recommended levels (Jamir, Nongkynrih, and Gupta 2014; Jamrah, Al-Omari, and Sharabi 2006; Zannin, Diniz, and Barbosa 2002; Oyedepo and Saadu 2009; Mehdi et al. 2011). In lab and field settings, increases in noise may not only induce anxiety and affect mood, but may also impair performance on cognitive tasks,

6. Emotions, such as disgust, can impact decision-making. For example, disgust has been shown in lab studies to decrease risk taking (Fessler, Pillsworth, and Flamson 2004) and reduce both sale and choice prices (Lerner, Small, and Loewenstein 2004). 
particularly those that require attention and memory (Szalma and Hancock 2011; Hygge, Boman, and Enmarker 2003; Boman, Enmarker, and Hygge. 2003; Enmarker, Boman, and Hygge 2006). Noise can increase the mental workload needed for a particular situation by acting as an annoyance or stressor, in effect limiting the available cognitive resources (Becker et al. 1995). Children are at an additionally increased risk of the negative impact of noise exposure and show impairments in reading comprehension, attention, and memory when exposed to noise (Stansfeld et al. 2005; Clark and Stansfeld 2007; Hygge, Evans, and Bullinger 2002). Though rigorous evidence on the effects of long-term exposure to noise pollution is scarce, there are a few studies that suggest that impacts may continue to exist despite individuals becoming accustomed to this noise. Irgens-Hansen et al. (2015) find that increased noise is associated with slower response times to a visual attention task among employees on board Royal Norwegian Navy vessels, where noise-exposure levels are consistently higher than recommended levels. Stansfeld et al. (2005) study the effect of chronic exposure to aircraft and road traffic noise on cognitive function in children and find associations between long-term exposure to aircraft noise and reading comprehension and recognition memory impairments, though they find no association with sustained attention. Further, there is suggestive evidence that prolonged exposure to noise may impact working memory (Hockey 1986; Szalma and Hancock 2011). However, lab evidence suggests that with longer exposure to continuous noise, agents can develop coping strategies that allow them to mitigate the effects of this noise (Szalma and Hancock 2011). Despite the above indications of impacts on cognitive function, there is a dearth of evidence regarding the potential downstream impacts of noise pollution on decisions and productivity.

Heat. Similarly, excessive heat has the potential to impede cognitive function and impair motivation. However, evidence to this effect is mixed (Gaoua 2011). This factor and its potential impacts are particularly relevant to life in developing countries, where the tropical environments and the lack of air conditioning make oppressive heat a near constant for many individuals. Existing evidence suggests that when exposed to an uncomfortably high temperature, reaction time and accuracy on attention, vigilance, and inhibitory control tasks are compromised (Simmons et al. 2008; Mazloumi et al. 2014). Moreover, exposure to excessive heat can impact productivity in manual work when the body is unable to maintain the appropriate core temperature (Kjellstrom, Holmer, and Lemke 2009). At the macro level, countries in hot climates have lower total agricultural output and economic growth, which

7. Given the long-term exposure to heat among those living in tropical regions, individuals do acclimatize to heat, which improves their physiological responses to heat exposure (Cheung and McLellan 1998; Fox et al. 1967). Radakovic et al. (2007) found that acclimation to heat did not improve performance on attention tasks; however, it did improve performance on more complex tests of cognitive function. 
could be partially explained by workers' reduced cognitive functioning (Dell, Jones, and Olken 2012). As global climate shifts continue to occur, studying these causal impacts will become even more central, with the majority of the burden borne by those in developing countries (Intergovernmental Panel on Climate Change 2014). Although few studies to date map the entire causal chain from extreme heat to economic decisions and outcomes, recent research explores the effects of oppressive heat on downstream effects such as reduced worker productivity in developing-country settings (Adhvaryu, Kala, and Nyshadham 2016; Burke, Hsiang, and Miguel 2015; Dell, Jones, and Olken 2012; Jones and Olken 2010; Hsiang 2010) and to an extent in developed-country settings as well (Deryugina and Hsiang 2014; Cachon, Gallino, and Olivares 2012).

Air Pollution. The prevalence of less energy-efficient technologies and the lack of strong enforcement mechanisms for pollution regulations make high levels of air pollution common for many individuals living in urban developing environments (McGranahan and Murray 2003). Not only do pollutants harm physical health (Seaton et al. 1995; Pope 2000; Ghio, Kim, and Devlin 2000) and decrease life expectancy (Greenstone et al. 2015; WHO 2014; Lim et al. 2012), but there is also suggestive evidence that air pollution may be linked to reduced worker productivity (Chang et al. 2016a, 2016b; Adhvaryu, Kala, and Nyshadham 2014; Graff Zivin and Neidell 2012) and cognitive impairments in domains including attention, processing speed, and memory (Tzivian et al. 2015; Lavy, Ebenstein, and Roth 2014; Weuve et al. 2012; Power et al. 2011; Franco Suglia et al. 2008). Air pollution has also been shown to decrease performance on high-stakes academic tests (Ebenstein, Lavy, and Roth 2016; Ham, Zweig, and Avol 2011). Though further research needs to be conducted to establish a causal link, recent research studies have also found a correlation between exposure to air pollution and rates of dementia and Alzheimer's disease (Cacciottolo et al. 2017; Chen et al. 2017).

\subsubsection{Stress and Depression}

While other channels are likely operating as well, poverty might also affect cognitive function and economic behavior via its impacts on stress and depression. Stress and depression are widely prevalent across the globe. An estimated 350 million people globally suffer from depression (WHO 2016). Moreover, there is reason to believe that the poor are disproportionately likely to suffer from these ailments. Income and socioeconomic status have well-known correlations with stress and anxiety (Chen, Cohen, and Miller 2010; Fernald and Gunnar 2009; Evans and English 2002; Lupien et al. 2001), with levels of the stress hormone cortisol (Cohen, Doyle, and Baum 2006; Li et al. 2007; Saridjana et al. 2010), and with depression (Lund et al. 2010; WHO 2001). Recent research using both natural experiments and randomized field experiments provides evidence that this relationship is causal, that is, that low income increases stress levels. For instance, using random rainfall shocks in Kenya, Chemin, de Laat, and Haushofer (2016) 
find that negative income shocks raise stress levels as measured by increases in the stress hormone cortisol. Randomized controlled trials support these findings, showing that a reduction in poverty caused by cash transfers reduces both stress and depression (Haushofer and Shapiro 2016; Baird, De Hoop, and Özler 2013; Ozer et al. 2011; Fernald and Gunnar 2009).

A growing body of evidence considers the role of mental health in the lives of the poor. Among them, a number of studies show that inducing stress in laboratory settings can increase risk aversion (Kandasamya et al. 2013; Mather, Gorlick, and Lighthall 2009; Porcelli and Delgado 2009; Cahlíková and Cingl 2017; Lighthall, Mather, and Gorlick 2009). In contrast, the evidence on stress's impact on time discounting is mixed (Cornelisse et al. 2014; Haushofer et al. 2013; Haushofer, Jang, and Lynham 2015). Furthermore, chronic stress in childhood is inversely related to working memory in adults (Evans and Schamberg 2009). Researchers have only recently begun to study the effects of depression on economic decision-making, with several studies currently in the field. While these initial results focused primarily on short-run impacts of stress and depression are interesting, much more evidence is needed to understand the how these factors affect economic outcomes outside of laboratory settings. Moreover, most research to date considers the impact of short-term changes in stress. However, individuals often live in poverty for extended periods, suggesting that studies to understand the longer-term impact of chronic stress and depression on economic outcomes are particularly promising avenues of research.

\subsection{Impact of Cognitive Functions on Economic Outcomes}

Building on the previous section, which highlighted links from poverty to changes in cognitive function, this section discusses the reverse linkages from cognitive function to economic outcomes. Considering linkages in both directions highlights the significant potential for feedback loops, or cycles of poverty centered on changes in bandwidth.

With subsections dedicated to each of the areas of cognitive function covered in section 2.2, we begin by discussing the existing evidence, both theoretical and empirical, for such impacts. Then we provide conceptual background on how changes in that area of cognitive function may impact economic outcomes and poverty in ways that have yet to be studied. Importantly, these discussions are not exhaustive; the number of potential pathways is sufficiently vast that we can only highlight a select set of illustrative examples in each area.

\subsubsection{Attention}

Attention, and its role in economic life, has generated growing interest in recent years. Economists have recognized that attention is a scarce resource, creating very real trade-offs. We first briefly review four modeling approaches of attention in economics as examples of this literature and discuss the 
existing empirical evidence bearing on the predictions of each model. We then outline other outcomes that may be the result of attentional constraints, making them particularly promising directions for future research.

\section{Theory}

Four main strands of research modeling the role of attention in shaping economic behaviors have been developed. To the best of our knowledge, however, direct tests of these models-for example, by considering the impact of increases or decreases in attention on the outcomes of interesthave not been conducted to date.

I. Rational Inattention. Consistent with evidence from cognitive psychology research, the rational inattention literature considers attention to be a limited resource. Optimizing agents subject to attentional constraints allocate their available attention among competing sources of differing value. Most prominent in this literature, Sims $(1998,2003)$ proposes a model of limited attention as an information flow with a bound, where information is quantified as a reduction in uncertainty that comes at a cost. This model has widespread applicability to many decisions. Among other topics, Sims's rational inattention model has been applied to price setting (Woodford 2012; Maćkowiak and Wiederholt 2009; Matějka 2016), consumption versus savings problems with constant (Sims 2006; Luo 2008) and variable interest rates (Maćkowiak and Wiederholt 2015), portfolio management (Van Nieuwerburgh and Veldkamp 2009; Mondria 2010), political campaigns (Gul and Pesendorfer 2012), and discrimination (Bartoš et al. 2016).

II. Sparsity. Gabaix $(2014,2016)$ presents a model of bounded rationality in which individuals "sparsely maximize" or only pay attention to certain attributes. In this framework, an agent faces a choice of actions and must choose among them to maximize her utility, with her optimal action dependent on multiple variables. The agent uses a two-step algorithm to choose her utility-maximizing action. First, she chooses a "sparse" model of the world by ignoring many of the variables that could affect her optimal action. Second, she chooses a boundedly rational action with this endogenously chosen sparse model of the world. For each decision a person faces, there may be hundreds of relevant attributes, and it would be difficult, if not impossible, to take each of these into account. While there are likely other factors at play as well, one potential consequence of a consumer choosing a "sparse" model of the world is the "stickiness" of choices and individuals' propensity to follow default options, for instance, in organ donation (Johnson and Goldstein 2003) or retirement savings decisions (Madrian and Shea 2001; Choi et al. 2006; Beshears et al. 2009), and in insurance markets (Handel 2013; Handel and Kolstad 2015; Bhargava, Loewenstein, and Sydnor 2015), even when other potentially dominating options become available.

III. Salience. A third strand of theory directly models the salience of different attributes (prices, product characteristics, etc.) for different options 
in an agent's choice set and environment. In these models, salient attributes are defined as attributes that consumers disproportionately focus on and therefore overweight in their decision-making process. The key questions in such models are then what influences which attributes individuals focus on and which attributes are salient in different environments. Three approaches of modeling salience have been proposed to date (Bordalo, Gennaioli, and Shleifer 2012, 2013; Köszegi and Szeidl 2013; Bushong, Rabin, and Schwartzstein. 2016). However, the empirical literature is yet to provide conclusive evidence testing the predictions of these theories against each other.

IV. Selective Attention. In a fourth strand of the economics literature on inattention, Schwartzstein (2014) details how selective attention can have persistent effects on belief formation and learning. Underlying Schwartzstein's model is the idea that what an agent attends to today is dependent on his or her current beliefs. Following from this, what the agent attends to today will then also affect his/her beliefs in the future. Accordingly, given an agent's incorrect initial beliefs or model of the world, this attentional strategy can lead to a failure to recognize important predictors or patterns (those outside the agent's existing model of the world), leading individuals to overlook key factors in their decision-making consistently and over long periods.

\section{Empirical Evidence}

To date, there is only limited empirical evidence directly testing the predictions of the above models, and in particular, evidence that can help to distinguish between the predictions of these models. As a result, it is likely too early to clearly predict how decreases in attentional constraints affect individuals' choices. However, one natural hypothesis is that an increase in attention (e.g., due to improved sleep) reduces biases in choice that the models discussed above predict and hence improves decision-making.

Empirical evidence for models centered on the role of attention can be found in a number of realms. We provide a few illustrative examples, but these effects are likely to apply much more broadly to areas such as savings, education, and health choices as well.

Technology Adoption. Hanna, Mullainathan, and Schwartzstein (2014) apply Schwartzstein's model to technology adoption in seaweed farming and demonstrate that even when people have repeated experience with a decision they may fail to notice important product attributes, and thus may fall continuously away from the production frontier. Similarly, Datta and Mullainathan (2014) note that programs to encourage the adoption of technology often fail and that it is essential that new users are attentive to certain features of the technology to use it effectively. Further, the selective-attention model has been used to explain low usage or nonadoption of technology or best practices. For instance, historically, there was delayed recognition of the importance of sterilizing operating rooms to prevent infections despite 
access to relevant data (Gawande 2004; Nuland 2004). Doctors had false beliefs about other causes of infection that prevented them from considering, or paying attention to, a simple, effective intervention such as hand washing. In a similar manner, Bloom et al. (2013) show that managers failed to adopt best practices in the Indian textile industry despite natural variation, which should permit learning about the importance of the attributes that contribute to best practices. However, to the best of our knowledge, there is no direct evidence linking changes in attention to changes in technology adoption.

Shrouded Attributes and Salience. A number of studies find that consumers pay only limited attention to taxes or certain product characteristics, often referred to as "shrouded attributes" (Gabaix and Laibson 2006). Accordingly, increasing or decreasing salience of these attributes can significantly affect sales (Chetty, Looney, and Kroft 2009; Gallagher and Muehlegger 2011), labor supply, and earnings behavior (Chetty and Saez 2013). In a study of commodity tax salience, Chetty, Looney, and Kroft (2009) find that a small increase in tax that is included in posted prices reduces demand more than when that tax is added to the price at the register. Although consumers are aware that the taxes exist (based on survey data), they fail to attend fully to these less-salient taxes at the time of purchase.

\section{Other Potential Pathways}

Despite the fact that attention receives more focus in the economics literature than most areas of cognitive function, there remain many unexplored ways in which constraints on attention may impact the lives of the poor.

Productivity. Existing theoretical work also links attention to poverty traps. Banerjee and Mullainathan (2008) present a model of poverty and attention based on the idea of attention scarcity. The authors note that wealthier individuals are likely to have access to goods that can reduce the attention required at home-for instance, water piped into their home or reliable childcare. The poor, who do not have access to distraction-limiting goods, are therefore more distracted at work, whereas the wealthier are able to devote more attention to work with less worry about problems at home, and thus the rich are more productive than the poor. While this is an intriguing hypothesis, direct empirical evidence of such effects is scarce.

Workplace and Traffic Accidents. Accidents are substantial concerns among the poor and are potentially driven in part by lapses in attention. The consequences of such attentional lapses may be larger for the poor, who often lack the safety nets or precautions that exist in more developed economies. Imagine a worker on a factory assembly line monotonously operating a machine, whose mind wanders off for a split second at the wrong moment. In many resource-poor settings, such a lapse often results in a serious accident. Similarly, consider the dire consequences of a driver who loses focus on a highway after hours of commuting every day. In fact, 41 percent of car 
crashes in the United States are estimated to be the result of recognition errors, including inattention (USDT 2008). Yet these lapse rates are likely to be significantly higher in developing countries where factors causing lapses, such as sleep deprivation or noise, are more prevalent and where the mechanisms to prevent accidents or mitigate their impacts, such as rumble strips, are less likely to be present.

Home Production and Childcare. Inattention to matters at home can have enormous consequences-for instance, not realizing a child is becoming sick or that a household good, such as water or kerosene, is running low. Lapses in attention can also cause more subtle and long-term consequences. For example, consider attending to one's children to ensure that they complete their homework, or that they stay healthy and safe. Although a single lapse may not have significant consequences, the effects are likely to compound and may have severe long-run welfare effects for the child, including increasing the likelihood of intergenerational transmission of poverty.

\subsubsection{Inhibitory Control}

An important aspect of inhibitory control is self-control-the ability to regulate one's behavior when faced with impulses and temptations in order to follow through on an intended plan. The study of self-control problems continues to receive enormous attention in the economics literature, including both theoretical and empirical work. Several excellent reviews survey this large body of work (Frederick, Loewenstein, and O'Donoghue 2002; DellaVigna 2009; Bryan, Karlan, and Nelson 2010).

\section{Theory}

To date, the two main strands of theoretical work on self-control that have been most influential are hyperbolic discounting and dual-self models.

Quasi-hyperbolic Discounting. Quasi-hyperbolic discounting theory is based on empirical findings that discounting is not time-invariant: individuals tend to put more weight on the immediate present than on the future (Frederick, Loewenstein, and O'Donoghue 2002). Laibson (1997) and O'Donoghue and Rabin (1999) formalize quasi-hyperbolic discounting models of these observed preferences, building on work by Strotz (1956), Phelps and Pollak (1968), and Akerlof (1991). These models have two parameters governing intertemporal preferences $-\delta$, the standard long-run discount factor, and $\beta$, the short-run parameter that represents the desire for immediate gratification. When $\beta<1$, discounting between the present and future periods is higher than between future time periods and the agent's preferences are time-inconsistent. A decision maker's awareness of his or her future preferences can have important effects on behavior. O'Donoghue and Rabin $(1999,2001)$ model expectations of future time preferences, and define three types of agents: (a) sophisticated agents who know they will exhibit present bias in the future; (b) naive agents, who falsely believe their future 
self is not present-biased; and (c) partially naive agents who know that they exhibit self-control issues, but underestimate the extent of the bias, causing these agents to be overconfident about their future level of self-control.

Dual-Self Models. The other prominent strand of theoretical work on self-control focuses on dual-self models (Fudenberg and Levine 2006; Gul and Pesendorfer 2001, 2004). Dual-self models differ in structure, but they all include a short-run self and a long-run self, which often find themselves in conflict. The short-run doer is myopic and mostly concerned with the present, while the long-run planner is concerned with lifetime utility (Thaler and Shefrin 1981). The long-run planner can exert influence over the short-run doer, but this comes at a cost (Fudenberg and Levine 2006). In a different type of dual-self model, the temptation-preference model of Gul and Pesendorfer (2001, 2004), agents consider preferences among choice sets. While most models of intertemporal choice assume that options not chosen are irrelevant to utility, Gul and Pesendorfer's model posits that agents experience disutility from not choosing the most tempting current option. Thus agents can avoid temptation, but there is an associated cost to this avoidance. Therefore, agents can benefit when they remove tempting options from their choice sets.

\section{Empirical Evidence}

A large empirical literature has considered how self-control problems influence economic behavior. However, cleanly identified evidence of the causal impact of income, wealth, or other factors that affect bandwidth on self-control and time preferences is scarce. More generally, we only have a limited understanding of the underlying determinants of self-control problems and causes of differences in self-control across people and within people over time. Moreover, to the best of our knowledge, no studies to date have considered the underlying determinants of individuals' naïveté regarding future self-control problems.

Borrowing, Saving, and Investing. A body of evidence suggests that selfcontrol problems interfere with low-income individuals' intertemporal choices. ${ }^{8}$ A number of studies detail instances in which the poor fail to take advantage of small and divisible high-return investment opportunities. Moreover, the poor are more likely to borrow at high interest rates, taking out loans routinely rather than only for emergencies (Aleem 1990; Karlan and Mullainathan 2010; Banerjee and Mullainathan 2010). Several studies find evidence that self-control impacts individuals' consumption-savings choices. Ashraf, Karlan, and Yin (2006) report high take-up rates and significantly increased savings due to a commitment savings product in the Philippines, revealing a causal impact of self-control problems on savings behavior. Dupas and Robinson (2013) find that study participants in a field

8. See Haushofer and Fehr (2014) for a discussion of poverty and time discounting. 
experiment in Kenya increase savings and benefit from access to simple, safe, savings accounts, as well as from earmarked savings accounts and Rotating Savings and Credit Associations (ROSCAs). However, among study participants with time-inconsistent preferences, access to a simple savings account and earmarked savings account did not increase savings, while access to ROSCAs did. This evidence suggests that providing access to safe savings technologies may not be sufficient to increase savings. Other factors-external societal pressure or commitment devices - might aid those with timeinconsistent preferences in achieving their desired long-run savings goals.

Consumption Choices. Beyond distortions in intertemporal choice, there is also evidence that self-control problems interfere with individuals' consumption choices across periods. Such evidence exists in particular for addictive goods. In line with Gruber and Köszegi (2001), Giné et al. (2010) find demand for a voluntary commitment product for smoking cessation in the Philippines, which produced moderate improvements in long-term smoking cessation. In a field study among low-income workers in India, Schilbach (2017) finds that about half of study participants exhibit demand for commitment to increase their sobriety, again revealing self-control problems. Moreover, about a third of participants were willing to give up at least ten percent of their daily incomes in order to receive incentives to remain sober.

Productivity. People who recognize that they suffer from self-control problems may seek commitment devices to improve their productivity. Ariely and Wertenbroch (2002) run experiments in which students are allowed to preemptively set due dates for school assignments, and find that students are willing to self-impose costly deadlines. While these self-imposed deadlines did improve overall performance, these deadlines were not set optimally. In a real-world work setting, Kaur, Kremer, and Mullainathan (2015) find evidence that self-control problems interfere with worker productivity. Employees at a data entry firm were offered weakly dominated "commitment" contracts, which paid less than the standard piece rate if a production target was not met, and the standard piece rate if the production target was met. The authors find substantial demand for commitment among the workers. Moreover, workers who were offered such commitment contracts were significantly more productive and enjoyed higher earnings.

\section{Other Potential Pathways}

While the study of self-control in poverty is already extensive, there are many ways in which potential cognitive changes that alter self-control can impact the lives of the poor. Health, education, and crime are potential channels that could be explored further. First, in addition to refraining from addictive substances that can harm health, self-control is essential for other health factors, such as attending yearly checkups at the doctor or maintaining a healthy weight. Rates of overweight and obesity are rising rapidly in many developing countries. As calories become less expensive and more 
readily and consistently available, individuals will require substantial selfcontrol in order to regulate intake and maintain a healthy weight. Second, self-control might have important implications for educational attainment. Students need to exercise self-control to be able to get up in the morning to attend class, pay attention to the teacher, study new material, and complete homework assignments. Deficiencies in self-control are likely to impact academic attendance, performance, and eventual achievement. Third, one prominent theory on crime, the "self-control" or "general" theory of crime, posits that low levels of individual self-control are the main factor driving criminal behavior (Gottfredson and Hirschi 1990). This view has received empirical support in the criminology literature (Pratt and Cullen 2000), as well as from recent research on cognitive behavior therapy (CBT) in Liberia (Blattman, Jamison, and Sheridan 2017).

As in the case of attention, lapses in self-control could be more costly for those living in poverty. Splurging on a tasty snack item or a new item of clothing is hardly a life-changing event for the wealthy. Among the poor, however, lapses in self-control can have far-reaching consequences, such as expensive cycles of debt as described above. Moreover, the self-control available might be systematically different for poorer individuals if they are exposed to more temptations in their everyday lives than the rich. However, while intriguing, there is no direct causal evidence of this hypothesis. Much more work in this area is needed.

\subsubsection{Memory}

There is a small but growing theoretical literature on the relationship between memory and economic outcomes. After briefly reviewing this literature, we discuss the related empirical evidence, which mainly focuses on memory's impacts on health and savings.

\section{Theory}

While economic theory on memory is less developed than the literature on attention or inhibitory control, a number of models do exist. We discuss three of these approaches.

Rehearsal and Associativeness. Mullainathan (2002) provides an economic model of memory limitations that can explain certain biases and empirical puzzles (e.g., over- or underreaction to news in financial markets). In doing so, Mullainathan (2002) draws on two constructs from the psychological and biological literatures on memory: rehearsal, the idea that it is easier to remember an event after having remembered it once before, and associativeness, the idea that it is easier to recall an event that is similar to current events. Both of these concepts affect how accessible a given memory is and can thus be explanations for observed behavioral biases.

The Cost of Keeping Track. Haushofer (2015) shows that keeping track of incomplete tasks generates costs to the agent in the form of financial 
consequences (e.g., late fees) and/or psychological consequences of keeping the task in mind. Haushofer models these costs as a lump sum, and shows that such costs can lead people to "pre-crastinate," or incur a loss in the present rather than in the future. Haushofer provides empirical support for his model using experimental evidence from Kenya. Haushofer notes that this model of memory can be valuable in many settings within development economics - for example, by providing options that do not require people to pay the cost of keeping track - such as providing chlorine at the place where water is collected rather than in the home, which has been shown to improve usage (Kremer et al. 2009).

Memory and Procrastination. Ericson (2017) describes how reminders can have significant effects on actions, yet deadlines - which should prompt agents to overcome present bias and act — are often ignored, even when such actions lead to substantial losses. ${ }^{9}$ Ericson shows that the interaction of present bias and memory can explain these phenomena. His model suggests that anticipated reminders, such as deadlines, can induce procrastination, while unexpected reminders might bring welfare-inducing actions to the top of mind, spurring action.

\section{Empirical Evidence}

A relatively large body of evidence demonstrates the importance of memory to economically important outcomes by providing evidence that reminders can effectively alter agents' behaviors. However, we are not aware of research that considers the direct impact of interventions to improve memory on economic outcomes.

Health. A large share of the evidence on reminders stems from the medical literature, in particular the literature on medical adherence (see Haynes et al. [2008] and Vervloet et al. [2012] for overviews). A relatively robust finding from this literature is that reminders typically have a modest but meaningful impact on healthful behaviors including smoking cessation (Free et al. 2011), adherence to medication and treatment regimens (Pop-Eleches et al. 2011; Dulmen et al. 2007; Krishna, Boren, and Balas 2009), and preventive health behaviors such as sunscreen use (Armstrong et al. 2009).

Savings. Conducting an experiment with commitment savings customers in Bolivia, Peru, and the Philippines, Karlan et al. (2016) show that reminders can increase savings. The authors vary reminders sent to customers and find that reminders increase savings and that reminders of specific future goals, which often require a high lumpy expense, are particularly effective at increasing savings. This evidence shows that memory and recall are partially responsible for low savings and suggests that reminding people of long-term

9. For example, King (2004) finds that students fail to apply for financial aid by the deadlines, and Pechmann and Silk (2013) find that people do not submit rebates prior to their expiration. 
goals can effectively alter behavior. Significant effects of reminders have also been found for loan repayments (Karlan, Morten, and Zinman, forthcoming; Cadena and Schoar 2011).

\section{Other Potential Pathways}

Memory also plays a central role in a wide range of other economic behaviors, as evidenced by the effectiveness of reminders in a wide variety of domains beyond the health applications above. Examples include donations (Damgaard and Gavert 2014), appointment sign-ups (Altmann and Traxler 2012) and show-ups (Guy et al. 2012), and rebate claims (Letzler and Tasoff 2014), among others. However, memory is central to economic outcomes beyond simply remembering to undertake tasks. In particular, working memory plays an important role in understanding language, doing mental math, updating information or actions, and considering alternatives. As such, improving working memory might affect a range of important behaviors and decisions, ranging from technology adoption among small-scale farmers to shopkeepers' inventory choices and low-income workers' decisions to (not) migrate to cities during lean seasons. Moreover, impediments to working memory are associated with higher discount rates and impulsiveness (Hinson, Jameson, and Whitney 2003). The ability to consider alternatives and make prudent, rather than impulsive, decisions is essential for sound long-run decision-making.

Although to the best of our knowledge unstudied to date, low levels of literacy may interact with memory in important ways. On the one hand, individuals with low literacy are forced to rehearse their memory on a daily basis as they are not able to write down instructions, directions, or other key information, which might improve their memory capacity. However, being forced to keep a lot of information in mind ties up existing mental resources, which in turn may reduce the cognitive capacity available to be devoted to other decisions and tasks. Take, for example, a farmer learning about a new fertilizer or seed variety. Remembering the advice of an agricultural extension agent for a number of months and then recalling it at the appropriate time might drain cognitive resources, which in turn may distort other important choices or result in a loss of other potentially valuable information. Such burdens are largely shouldered by the poor due to their lower levels of literacy and numeracy.

\subsubsection{Higher-Order Executive Functions}

Compared to other components of cognitive function, economic theory and empirical evidence on higher-order executive functions are less developed. We posit a number of areas where these functions may play an important role in behavior and decision-making and provide some suggestive empirical evidence on these effects. 


\section{Theory}

Economists would likely all agree with the notion that intelligence and planning affect economic outcomes in important ways. However, the economic theory machinery to map changes in higher-order executive functions into economic behavior is yet to be developed. We therefore focus on existing empirical evidence.

\section{Empirical Evidence}

Below we outline the existing empirical evidence regarding the role of cognitive flexibility, intelligence, and planning in shaping economic behavior.

Optimization Behavior. Traditional economic theory posits that agents optimize their choices based on their preferences, beliefs, and constraints. Therefore, given the same choice set with the same preferences and information, agents should make the same utility-optimizing choices. However, research shows that this is not always the case and that in certain situations decision-making is inconsistent (Famulari 1988; Sippel 1997; Février and Visser 2004). Recent research shows that cognitive ability, measured using a variation of the Raven's matrices test and the Cognitive Reflection Test (Frederick 2005), may also be related to inconsistent or seemingly random decision-making (Andersson et al. 2016). Choi et al. (2014) test for consistency in utility maximization and find that consistency scores vary significantly within and across socioeconomic groups, with consistency particularly strongly related to wealth. Poorer individuals exhibit lower consistency even when controlling for unobserved constraints, preferences, and beliefs. However, we do not know whether this relationship is causal. There exists no direct evidence that increasing income or wealth (for instance, via cash transfers) improves choice consistency.

Innovation and Creativity. Psychologists widely regard cognitive flexibility to be an important aspect of both innovation and creativity (Chi 1997; Jaušovec 1991, 1994; Runco and Okuda 1991; Thurston and Runco 1999; Torrance 1974). Cognitive flexibility can facilitate creativity, and thereby increase innovation by helping individuals see a problem from a new perspective and shift strategies to more efficiently solve a problem (Thurston and Runco 1999; Okuda, Runco, and Berger 1991). Higher-order thinking can also enable individuals to switch between conceptual ideas and thus avoid getting stuck on one piece of a problem.

Labor Market Outcomes. There is a wide body of literature that highlights the importance of cognitive skills, often measured by intelligence scores, in predicting wages (Murnane, Willett, and Levy 1995), on-the-job performance and training success (Bishop 1991), and schooling (Cawley, Heckman, and Vytlacil 2001). Assessing the effects of general intelligence on future labor market success is difficult given that it is so strongly and inextricably 
correlated with educational attainment, making measurement of the separate effects of these factors difficult or impossible (Cawley, Heckman, and Vytlacil 2001; Heckman and Vytlacil 2001). However, even controlling for educational attainment, Judge, Hurst, and Simon (2009) find that general mental ability (as measured by a battery of tests including Raven's matrices and the Wechsler Intelligence Test) has a significant direct effect on income levels. Further, the authors find that general mental ability has significant indirect effects on income through its impact on education and self-esteem. Results from developing countries are more mixed. Psacharopoulos and Velez (1992) find that intelligence — as measured by Raven's matrices testaccounts for a small portion of the return to education on wages in Colombia. Fafchamps and Quisumbing (1999) find that, controlling for education, intelligence as measured by the Raven's matrices test, has an insignificant effect on earnings from crops, livestock, and nonfarm labor in rural Pakistan. Vogl (2014) studies the height premium on wages in Mexico - the additional wages associated with being taller — and finds that cognitive ability, as measured by the Raven's matrices test, accounts for only a small share of the height premium, while educational attainment and occupational selection account for approximately half this premium. However, Vogl suggests that cognitive ability may play an important role through its indirect effects on educational attainment and occupational sorting.

\section{Other Potential Pathways}

In addition to the empirical evidence outlined above, we hypothesize that higher-order executive functions may play a role in other areas of economic interest.

Technology Adoption. To be willing to adopt a given technology, agents must be willing and able to see themselves and their surroundings in other states of the world. For instance, a farmer considering the adoption of a new crop must foresee and plan how to sell the crop in the subsequent season. Such flexibility and planning is essential as the investment needed to adopt a new technology generally takes place prior to the realization of benefits. In short, it is necessary to be able to imagine the potential costs and benefits of the technology prior to adopting it. Moreover, the ability to accurately learn about the costs and benefits of new technologies likely directly depends on higher-order cognitive functions and, in particular, fluid intelligence.

Resilience. Cognitive flexibility is a key component of resilience. It allows individuals to reframe or reappraise a situation instead of getting stuck in a particular mind-set, providing more potential solutions to a problem. Further, cognitive flexibility enables individuals to reevaluate and adjust their perceptions of difficult and traumatic events, which can help them to understand the trauma and recover from it. For example, after surviving a traumatic event, cognitive flexibility can enable an individual to maintain the belief that he or she will prevail despite the difficulties of life. 
Cooperation. Cognitive flexibility even has the potential to effect cooperation and interpersonal relationships. Consider interpersonal disagreements or conflicts - the ability to see the world through the eyes of others is often helpful in order to resolve conflict when there are different preferences or opinions. This, in turn, could have potential implications in models of household bargaining, social cohesion and trust, and workplace relationships.

\subsection{Open Questions and Future Research Directions}

Cognitive function and its implications for human behavior and economic outcomes are not poverty-specific - they are applicable in a much broader range of settings and across many income levels. However, understanding the relationship between cognitive function and economic behavior is particularly relevant to the study of economic development and poverty because poverty may be both a cause and a consequence of changes in cognitive function. An adult's cognitive ability is traditionally considered fixed. However, recent evidence shows that it is variable and can be affected by circumstances. Poverty has associated hardships-lack of nutritious food, limited access to medical care, difficult working conditions, and the stress of paying bills - which all have the potential to impair cognitive ability. Shifts in cognitive ability, in turn, can lead to diminished productivity and impaired decision-making, thus potentially deepening poverty and creating a feedback loop that may even generate the potential for poverty traps.

Although some evidence of this potential exists, much remains unknown regarding the exact nature of the bidirectional relationships between areas of cognitive function and poverty. This relative paucity of knowledge generates an open and valuable area of research to pursue. How do poverty and environment shape cognitive function, and how does cognitive function shape economic outcomes? There are specific components of poverty that have already been studied and shown to affect cognitive ability, such as scarcity (Mani et al. 2013) and poor nutrition (Schofield 2014). Yet numerous other components and correlates of poverty may affect cognitive function in ways that are not yet well understood, such as lack of sleep, chronic pain, or noise and air pollution. Beyond these relationships, there are many other valuable directions of inquiry in this area to understand these relationships comprehensively, and in doing so, potentially inform both basic knowledge and policy. For example, does long-run exposure to aspects of poverty (e.g., chronic physical pain or sleep deprivation) increase or decrease the associated impacts on cognitive function and economic behavior? Should policies target poverty, leading to improvements in cognitive function, or should they target improvements in cognitive function to reduce poverty? Are there important interaction effects between different aspects of life in poverty? Are individuals aware of the effects of poverty and do they adjust their behavior accordingly (e.g., by avoiding to make important choices while being tired 
or in pain)? What is the correlation of different aspects of cognitive function between and within individuals? Is bandwidth an asset that can be accumulated, generating a reserve?

Seeking a deeper, more nuanced understanding of cognitive function has enormous potential to help us understand the causes and consequences of poverty. Although a broad topic with many overlapping aspects, cognitive function does consist of measurable and reasonably distinct components. In this chapter we have outlined four components of cognitive function that are important to economics - attention, inhibitory control, memory and working memory, and higher-order executive functions, which include cognitive flexibility, fluid and crystallized intelligence, and planning. While we know a fair amount about how to measure cognitive function, we know far less about its influence on productivity and decision-making. Now that the tools are available, there is a lot more to be learned. 


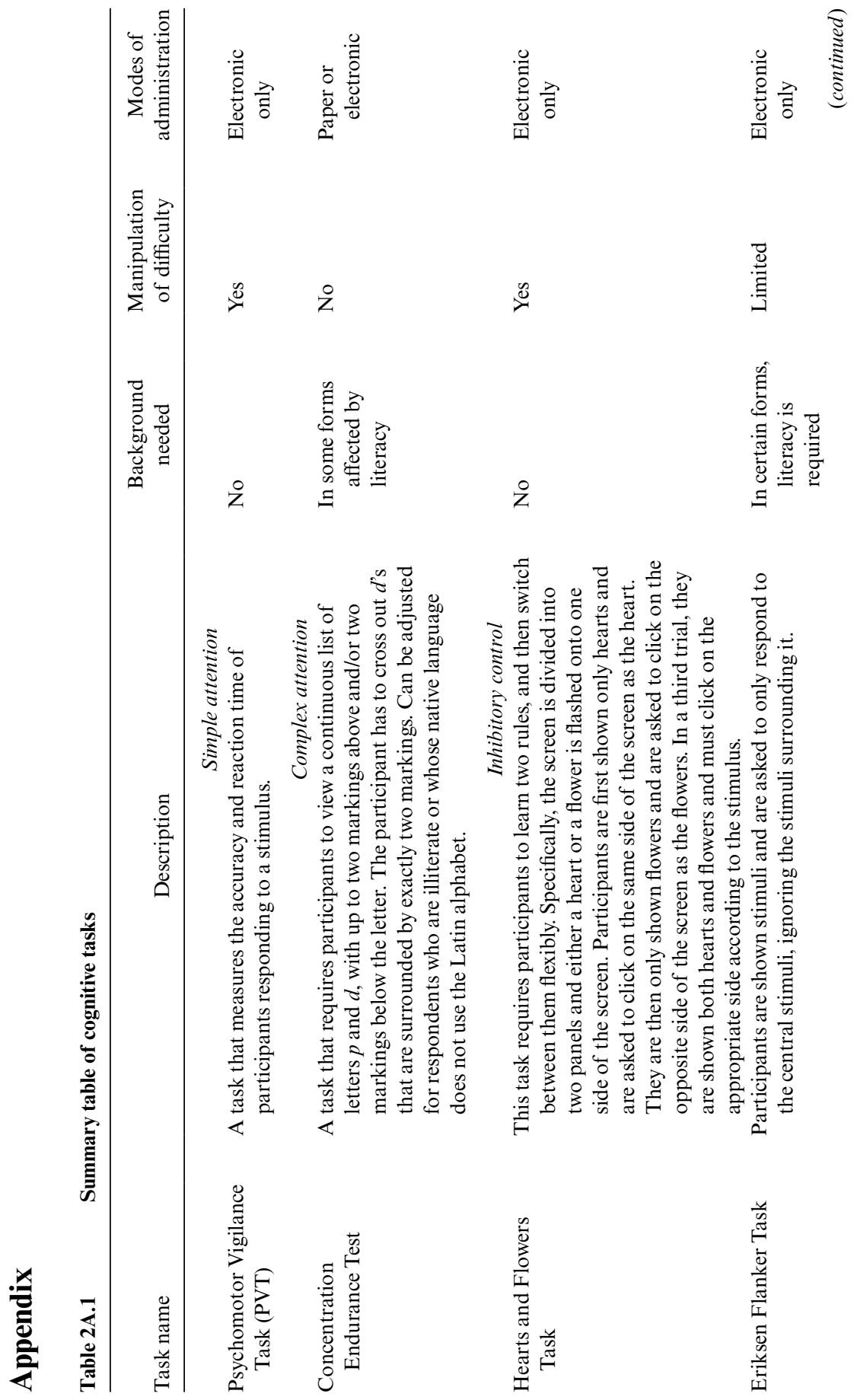




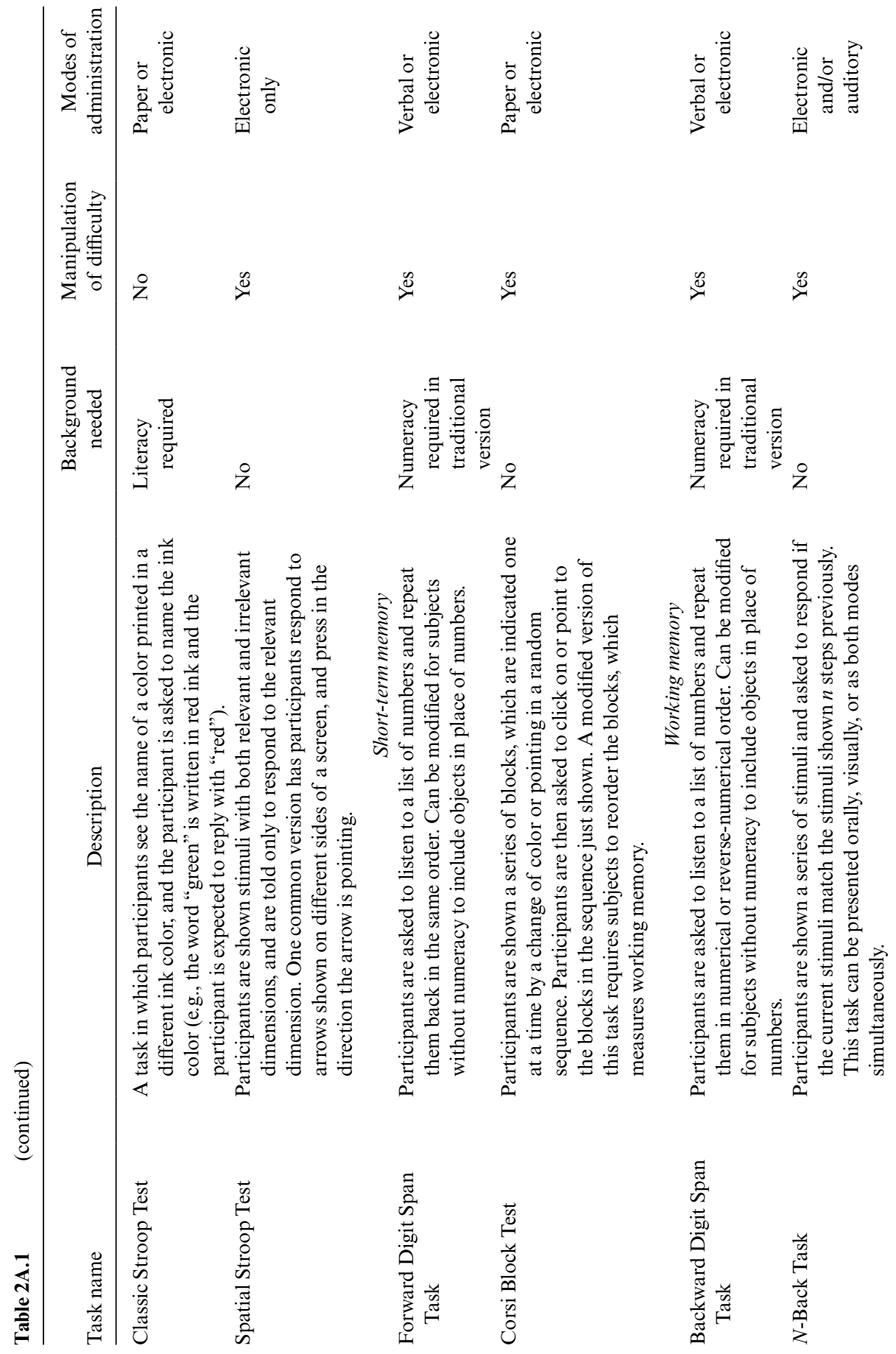



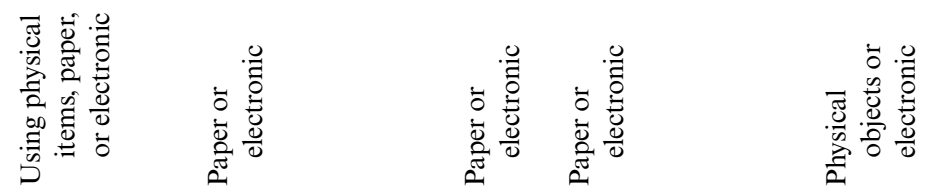

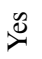

‡̊

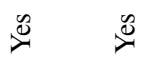

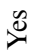

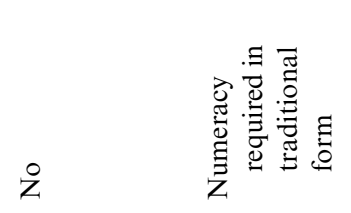

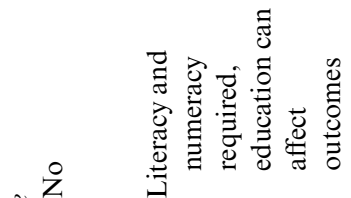

to

氖.

ช

需

릉.

i

है

要 密

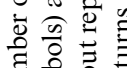

䒠 है

ส

जे के

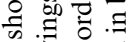

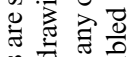

䒕 元

융 巳 :

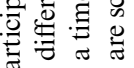

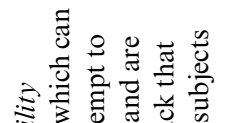<smiles>[Te][W]#[W]</smiles>

气

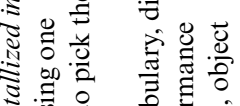

范 论

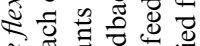

ष्ञ

की

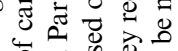

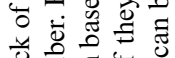

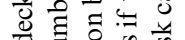

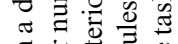

売 0.

$3 \stackrel{0}{0} .0$

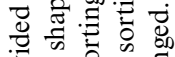

రิt

ग

สิ

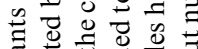

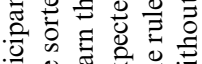

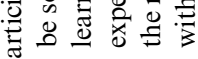

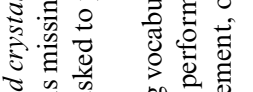

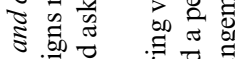

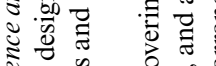

总.0

水

:

胥

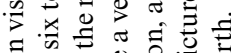

की

की

むँ

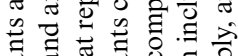

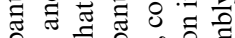

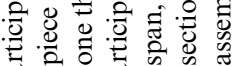

z

च ल

ㅎํㅇำ

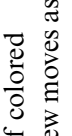

$\approx$ ○

竞

$\frac{\pi}{\omega} \cdot \exists$

응.

艛

E

50 ㄷㅇ

ठ․

都

递

齐

을

政

홍

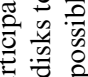

党

.
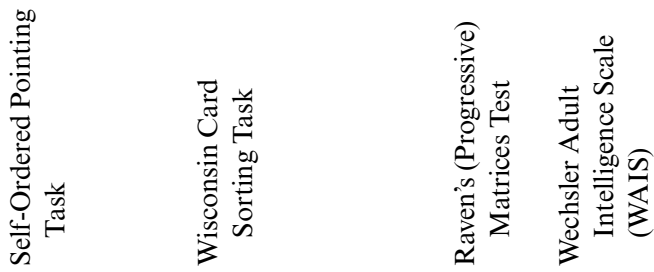

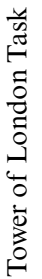




\section{References}

Adhvaryu, Achyuta, Namrata Kala, and Anant Nyshadham. 2014. "Management and Shocks to Worker Productivity: Evidence from Air Pollution Exposure in an Indian Garment Factory." Working paper, Department for International Development.

. 2016. "The Light and the Heat: Productivity Co-benefits of Energy-Saving Technology." Working paper, University of Michigan.

Akerlof, George. 1991. "Procrastination and Obedience." American Economic Review Papers and Proceedings 81 (2): 1-19.

Aleem, Irfan. 1990. "Imperfect Information, Screening, and the Costs of Informal Lending: A Study of a Rural Credit Market in Pakistan." World Bank Economic Review 4 (3): 329-49.

Altmann, Steffan, and Christian Traxler. 2012. "Nudges at the Dentist." IZA Discussion Paper no. 6699, Institute of Labor Economics.

Andersson, Ola, Håkan J. Holm, Jean-Robert Tyran, and Erik Wengström. 2016. "Risk Aversion Relates to Cognitive Ability: Preferences or Noise?" Journal of the European Economic Association 14 (5): 1129-54.

Andrewes, David G. 2001. Neuropsychology: From Theory to Practice, 2nd ed. East Sussex, UK: Psychology Press.

Ariely, Dan, and Klaus Wertenbroch. 2002. "Procrastination, Deadlines, and Performance: Self-Control by Precommitment." Psychological Science 13 (3): 219-24.

Armstrong, April W., Alice J. Watson, Maryanne Makredes, Jason E. Frangos, Alexandra B. Kimball, and Joseph C. Kvedar. 2009. "Text-Message Reminders to Improve Sunscreen Use: A Randomized, Controlled Trial Using Electronic Monitoring." Archives of Dermatology 145 (11): 1230-36.

Ashraf, Nava, Dean Karlan, and Wesley Yin. 2006. "Tying Odysseus to the Mast: Evidence from a Commitment Savings Product in the Philippines." Quarterly Journal of Economics 121 (2): 635-72.

Baddeley, Alan D., and Graham Hitch. 1974. "Working Memory." In The Psychology of Learning and Motivation, vol. 8, edited by Gordon H. Bower, 47-89. Cambridge, MA: Academic Press.

Baird, Sarah, Jacobus De Hoop, and Berk Özler. 2013. "Income Shocks and Adolescent Mental Health.” Journal of Human Resources 48 (2): 370-403.

Bandiera, Oriana, Robin Burgess, Narayan Das, Selim Gulesci, Imran Rasul, and Munshi Sulaiman. 2015. "Labor Markets and Poverty in Village Economies." STICERD-Economic Organisation and Public Policy Discussion Papers Series no. 058, Suntory and Toyota International Centres for Economics and Related Disciplines.

Banerjee, Abhijit, and Esther Duflo. 2011. Poor Economics: A Radical Rethinking of the Way to Fight Global Poverty. New York: PublicAffairs.

Banerjee, Abhijit, Esther Duflo, Nathanael Goldberg, Dean Karlan, Robert Osei, William Parienté, Jeremy Shapiro, Bram Thuysbaert, and Christopher Udry. 2015. "A Multifaceted Program Causes Lasting Progress for the Poor: Evidence from Six Countries.” Science 348 (6236). https://doi.org/10.1126/science.1260799.

Banerjee, Abhijit, and Sendhil Mullainathan. 2008. "Limited Attention and Income Distribution.” American Economic Review Papers \& Proceedings 98 (2): 489-93. . 2010. "The Shape of Temptation: Implications for the Economic Lives of the Poor.” NBER Working Paper no. 15973, Cambridge, MA.

Banich, Marie T. 2009. "Executive Function: The Search for an Integrated Account." Current Directions in Psychological Science 18 (2): 89-94. 
Barrett, Christopher B., and Michael R. Carter. 2013. "The Economics of Poverty Traps and Persistent Poverty: Empirical and Policy Implications." Journal of Development Studies 49 (7): 976-90.

Barrett, Christopher B., Teevrat Garg, and Linden McBride. 2016. "Well-Being Dynamics and Poverty Traps." Annual Review of Resource Economics 8:303-27.

Bartoš, Vojtěch, Michal Bauer, Julie Chytilová, and Filip Matějka. 2016. "Attention Discrimination: Theory and Field Experiments with Monitoring Information Acquisition.” American Economic Review 106 (6): 1437-75.

Basner, Mathias, and David F. Dinges. 2011. "Maximizing Sensitivity of the Psychomotor Vigilance Test (PVT) to Sleep Loss.” Sleep 34 (5): 581-91.

Basner, Mathias, Daniel Mollicone, and David F. Dinges. 2011. "Validity and Sensitivity of a Brief Psychomotor Vigilance Test (PVT-B) to Total and Partial Sleep Deprivation." Acta Astronautica 69 (1): 949-59.

Basner, Mathias, Hengyi Rao, Namni Goel, and David F. Dinges. 2013. "Sleep Deprivation and Neurobehavioral Dynamics." Current Opinion in Neurobiology 23 (5): 854-63.

Bates, Marsha E., and Edward P. Lemay. 2004. "The d2 Test of Attention: Construct Validity and Extensions in Scoring Techniques." Journal of the International Neuropsychological Society 10 (3): 392-400.

Baumeister, Roy F. 2002. "Yielding to Temptation: Self-Control Failure, Impulsive Purchasing, and Consumer Behavior." Journal of Consumer Research 28 (1): 670-76.

Baumeister, Roy F., Ellen Bratslavsky, Mark Muraven, and Dianne M. Tice. 1998. "Ego Depletion: Is the Active Self a Limited Resource?" Journal of Personality and Social Psychology 74 (5): 1252-65.

Baumeister, Roy F., and Kathleen D. Vohs. 2007. "Self-Regulation, Ego Depletion, and Motivation." Social and Personality Psychology Compass 1 (1): 115-28.

Becker, Ami B., Joel S. Warm, William N. Dember, and Peter A. Hancock. 1995. "Effects of Jet Engine Noise and Performance Feedback on Perceived Workload in a Monitoring Task." International Journal of Aviation Psychology 5 (1): 49-62.

Ben-David, Itzak, and Marieke Bos. 2017. "Impulsive Consumption and Financial Wellbeing: Evidence from an Increase in the Availability of Alcohol." NBER Working Paper no. 23211, Cambridge, MA.

Berg, Esta A. 1948. "A Simple Objective Technique for Measuring Flexibility in Thinking." Journal of General Psychology 39:415-22.

Beshears, John, James J. Choi, David Laibson, and Brigitte C. Madrian. 2009. "The Importance of Default Options for Retirement Saving Outcomes: Evidence from the United States." In Social Security Policy in a Changing Environment, edited by Gary Burtless, 167-95. Chicago: University of Chicago Press.

Beshears, John, Katherine L. Milkman, and Joshua Schwartzstein. 2016. "Beyond Beta-Delta: The Emerging Economics of Personal Plans." American Economic Review 106 (5): 430-34.

Bhargava, Saurabh, George Loewenstein, and Justin Sydnor. 2015. "Do Individuals Make Sensible Health Insurance Decisions? Evidence from a Menu with Dominated Options." NBER Working Paper no. 21160, Cambridge, MA.

Bishop, John H. 1991. "The Impact of Academic Competencies on Wages, Unemployment and Job Performance." CAHRS Working Paper no. 91-34, Center for Advanced Human Resource Studies, Cornell University.

Blattman, Christopher, Julian C. Jamison, and Margaret Sheridan. 2017. "Reducing Crime and Violence: Experimental Evidence from Cognitive Behavioral Therapy in Liberia." American Economic Review 107 (4): 1165-206. 
Bliss, Christopher, and Nicholas Stern. 1978. "Productivity, Wages, and Nutrition: Part I: The Theory." Journal of Development Economics 5 (4): 331-62.

Bloom, Nicholas, Benn Eifert, Aprajit Mahajan, David McKenzie, and John Roberts. 2013. "Does Management Matter? Evidence from India." Quarterly Journal of Economics 128:1-51.

Boman, Eva, Ingela Enmarker, and Staffan Hygge. 2003. "Strength of Noise Effects on Memory as a Function of Noise Source and Age." Noise \& Health 7 (27): 11-26.

Bordalo, Pedro, Nicola Gennaioli, and Andrei Shleifer. 2012. "Salience Theory of Choice under Risk." Quarterly Journal of Economics 127 (3): 1243-85.

. 2013. "Salience and Consumer Choice." Journal of Political Economy 121 (5): 803-43.

Borella, Erika, Barbara Carretti, and Santiago Pelegrina. 2010. "The Specific Role of Inhibition in Reading Comprehension in Good and Poor Comprehenders." Journal of Learning Disabilities 43 (6): 541-52.

Broadbent, Donald. 1958. Perception and Communication. London: Pergamon Press.

Brunetti, Riccardo, Claudia Del Gatto, and Franco Delogu. 2014. "eCorsi: Implementation and Testing of the Corsi Block-Tapping Task for Digital Tablets." Frontiers in Psychology 5:1-8.

Bryan, Gharad, Dean Karlan, and Scott Nelson. 2010. "Commitment Devices." Annual Review of Economics 2:671-98.

Burke, Marshall, Solomon M. Hsiang, and Edward Miguel. 2015. "Global Nonlinear Effect of Temperature on Economic Production." Nature 527:235-39.

Bushong, Ben, Matthew Rabin, and Josh Schwartzstein. 2016. "A Model of Relative Thinking." Working paper, Harvard Business School, Harvard University.

Cacciottolo, Mafalda, Xinhui Wang, Ira Driscoll, Nicholas Woodward, Arian Saffari, Jeanette Reyes, Mark L. Serre, et al. 2017. "Particulate Air Pollutants, APOE Alleles and their Contributions to Cognitive Impairment in Older Women and to Amyloidogenesis in Experimental Models." Translational Psychiatry 7:1-8.

Cachon, Gerard P., Santiago Gallino, and Marcelo Olivares. 2012. "Severe Weather and Automobile Assembly Productivity." Columbia Business School Research Paper no. 12-37, Columbia University.

Cadena, Ximena, and Antoinette Schoar. 2011. "Remembering to Pay? Reminders vs. Financial Incentives for Loan Payments.” NBER Working Paper no. 17020, Cambridge, MA.

Cahlíková, Jana, and Lubomir Cingl. 2017. "Risk Preferences under Acute Stress." Experimental Economics 20 (1): 209-36.

Canas, Jose J., Jose F. Quesada, Adoracion Antoli, and Inmaculada Fajardo. 2002. "Cognitive Flexibility and Adaptability to Environmental Changes in Dynamic Complex Problem-Solving Tasks." Ergonomics 46 (5): 482-501.

Carlin, Danielle, Joy Bonerba, Michael Phipps, Gene Alexander, Mark Shapiro, and Jordan Grafman. 2000. "Planning Impairments in Frontal Lobe Dementia and Frontal Lobe Lesion Patients.” Neuropsychologia 38 (5): 655-65.

Carlson, Stephanie M., and Louis J. Moses. 2001. "Individual Differences in Inhibitory Control and Children's Theory of Mind." Child Development 72 (4): 1032-53.

Carvalho, Leandro, Stephan Meier, and Stephanie Wang. 2016. "Poverty and Economic Decision-Making: Evidence from Changes in Financial Resources at Payday.” American Economic Review 106 (2): 260-84.

Case, Anne, and Angus Deaton. 2015. "Rising Morbidity and Mortality in Midlife among White Non-Hispanic Americans in the 21st Century." Proceedings of the National Academy of Sciences USA (PNAS) 112 (49): 15078-83.

Cattell, Raymond B. 1963. "Theory of Fluid and Crystallized Intelligence: A Critical Experiment.” Journal of Educational Psychology 54 (1): 1-22. 
Cattell, Raymond B., and John L. Horn. 1966. "Refinement and Test of the Theory of Fluid and Crystallized General Intelligence." Journal of Educational Psychology 57 (5): 253-70.

Cawley, John, James Heckman, and Edward Vytlacil. 2001. "Three Observations on Wages and Measured Cognitive Ability." Labour Economics 8 (4): 419-42.

Centers for Disease Control and Prevention. 2015. "Quickstats: Percentage of Adults Who Average $\leq 6$ Hours of Sleep, by Family Income Group and Metropolitan Status of Residence, National Health Interview Survey, United States, 2013." Accessed September 5, 2016. http://www.cdc.gov/mmwr/preview/mmwrhtml/mm6412a10.htm.

Chang, Tom, Joshua Graff Zivin, Tal Gross, and Matthew Neidell. 2016a. "The Effect of Pollution on Worker Productivity: Evidence from Call-Center Workers in China." NBER Working Paper no. 22328, Cambridge, MA.

- 2016b. "Particulate Pollution and the Productivity of Pear Packers." American Economic Journal: Economic Policy 8 (3): 141-69.

Chemin, Matthieu, Joost de Laat, and Johannes Haushofer. 2016. "Negative Rainfall Shocks Increase Levels of the Stress Hormone Cortisol among Poor Farmers in Kenya." Working paper. Available at https://papers.ssrn.com/sol3/papers .cfm?abstract_id=2294171.

Chen, Edith, Sheldon Cohen, and Gregory E. Miller. 2010. "How Low Socioeconomic Status Affects 2-Year Hormonal Trajectories in Children." Psychological Science 21 (1): 31-37.

Chen, Hong, Jeffrey C. Kwong, Ray Copes, Karen Tu, Paul J. Villeneuve, Aaron van Donkelaar, Perry Hystad, et al. 2017. "Living Near Major Roads and the Incidence of Dementia, Parkinson's Disease, and Multiple Sclerosis: A Population-Based Cohort Study." Lancet 389 (10070): 718-26.

Chetty, Raj, Adam Looney, and Kory Kroft. 2009. "Salience and Taxation: Theory and Evidence." American Economic Review 99 (4): 1145-77.

Chetty, Raj, and Emmanuel Saez. 2013. "Teaching the Tax Code: Earnings Responses to an Experiment with EITC Recipients." American Economic Journal: Applied Economics 5 (1): 1-31.

Cheung, Stephen S., and Tom M. McLellan. 1998. "Heat Acclimation, Aerobic Fitness, and Hydration Effects on Tolerance during Uncompensable Heat Stress." Journal of Applied Physiology 84 (5): 1731-39.

Chi, Michelene T. H. 1997. "Creativity: Shifting across Ontological Categories Flexibly." In Creative Thought: An Investigation of Conceptual Structures and Processes, edited by Thomas B. Ward, Steven M. Smith, and Jyotsna Vaid, 209-34. Washington, DC: American Psychological Association.

Choi, James, David Laibson, Brigitte Madrian, and Andrew Metrick. 2006. "Saving for Retirement on the Path of Least Resistance." In Behavioral Public Finance, edited by Edward McCaffrey and Joel Slemrod, 304-52. New York: Russell Sage.

Choi, Syngjoo, Shachar Kariv, Wieland Müller, and Dan Silverman. 2014. "Who Is (More) Rational?" American Economic Review 104 (6): 1518-50.

Chou, Eileen Y., Bidhan L. Parmar, and Adam D. Galinsky. 2016. "Economic Insecurity Increases Physical Pain.” Psychological Science 27 (4): 1-12.

Chun, Marvin M., Julie D. Golomb, and Nicholas B. Turk-Browne. 2011. "A Taxonomy of External and Internal Attention." Annual Review of Psychology 62 (1): 73-101.

Clark, Charlotte, and Stephen A. Stansfeld. 2007. "The Effect of Transportation Noise on Health and Cognitive Development: A Review of Recent Evidence." International Journal of Comparative Psychology 20 (2): 145-58.

Cohen, Ronald A. 2014. The Neuropsychology of Attention, 2nd ed. New York: Springer US. 
Cohen, Sheldon, William J. Doyle, and Andrew Baum. 2006. "Socioeconomic Status Is Associated with Stress Hormones." Psychosomatic Medicine 68 (3): 414-20.

Cornelisse, Sandra, Vanessa van Ast, Johannes Haushofer, Maayke Seinstra, and Marian Joëls. 2014. "Time-Dependent Effect of Hydrocortisone Administration on Intertemporal Choice." Working paper. Available at https://papers.ssrn.com /sol3/papers.cfm?abstract_id=2294189.

Corsi, Philip M. 1972. "Human Memory and the Medial Temporal Region of the Brain.” Dissertation Abstracts International 34:819B.

Costa-Font, Joan, and Sarah Flëche. 2017. "Parental Sleep and Employment: Evidence from a British Cohort Study." CEP Discussion Paper no. dp1467, Centre for Economic Performance.

Cowan, Nelson. 2008. "What Are the Differences between Long-Term, Short-Term, and Working Memory?" Progress in Brain Research 169: 323-38.

Currie, Janet, and Douglas Almond. 2011. "Human Capital Development before Age Five." Handbook of Labor Economics 4:1315-486.

Czeisler, Charles A., Martin C. Moore-Ede, and Richard H. Coleman. 1982. "Rotating Shift Work Schedules That Disrupt Sleep Are Improved by Applying Circadian Principles." Science 217 (4558): 460-63.

Damgaard, Mette, and Christina Gavert. 2014. "Now or Never! The Effect of Deadlines on Charitable Giving: Evidence from a Natural Field Experiment." Economics Working Paper no. 2014-03, Department of Economics and Business Economics, Aarhus University.

Daneman, Meredyth, and Patricia A. Carpenter. 1980. "Individual Differences in Working Memory and Reading." Journal of Verbal Learning and Verbal Behavior 19 (4): 450-66.

-1983. "Individual Differences in Integrating Information between and within Sentences." Journal of Experimental Psychology: Learning, Memory, and Cognition 9 (4): 561-84.

Danziger, Shai, Jonathan Levav, and Liora Avnaim-Pesso. 2011. "Extraneous Factors in Judicial Decisions." Proceedings of the National Academy of Sciences USA (PNAS) 108 (7): 6889-92.

Dasgupta, Partha, and D. Ray. 1986. "Inequality as a Determinant of Malnutrition and Unemployment: Theory." Economic Journal 96 (384): 1011-34.

Datta, Saugato, and Sendhil Mullainathan. 2014. "Behavioral Design: A New Approach to Development Policy." Review of Income and Wealth 60 (1): 7-35.

Davidson, Matthew C., Dima Amso, Loren C. Anderson, and Adele Diamond. 2006. "Development of Cognitive Control and Executive Functions from 4 to 13 Years: Evidence from Manipulations of Memory, Inhibition, and Task Switching." Neuropsychologia 44 (11): 2037-78.

de Frias, Cindy M., Roger A. Dixon, and Esther Strauss. 2006. "Structure of Four Executive Functioning Tests in Healthy Older Adults." Neuropsychology 20 (2): 206-14.

Dell, Melissa, Benjamin F. Jones, and Benjamin A. Olken. 2012. "Temperature Shocks and Economic Growth: Evidence from the Last Half Century." American Economic Journal: Macroeconomics 4 (3): 66-95.

DellaVigna, Stefano. 2009. "Psychology and Economics: Evidence from the Field." Journal of Economic Literature 47 (2): 315-72.

Dempster, Frank N. 1992. "The Rise and Fall of the Inhibitory Mechanism: Toward a Unified Theory of Cognitive Development and Aging." Developmental Review 12 (1): 45-75.

Deryugina, Tatyana, and Solomon M. Hsiang. 2014. "Does the Environment Still Matter? Daily Temperature and Income in the United States." NBER Working Paper no. 20750, Cambridge, MA. 
Diamond, Adele. 2013. "Executive Functions." Annual Review of Psychology 64:135-68.

Diamond, Adele, W. Steven Barnett, Jessica Thomas, and Sarah Munro. 2007. "Preschool Program Improves Cognitive Control." Science 318:1387-88.

Diamond, Adele, and Colleen Taylor. 1996. "Development of an Aspect of Executive Control: Development of the Abilities to Remember What I Said and to 'Do as I Say, Not as I Do."” Developmental Psychobiology 29 (4): 315-34.

Dickinson, David L., and Todd McElroy. 2010. "Rationality around the Clock: Sleep and Time-of-Day Effects on Guessing Game Responses." Economics Letters 108 (2): $245-48$.

. 2016. "Sleep Restriction and Time-of-Day Impacts on Simple Social Interaction." IZA Discussion Paper no. 9673, Institute of Labor Economics.

Dinges, David F., Frances Pack, Katherine Williams, Kelly A. Gillen, John W. Powell, Geoffrey E. Ott, Caitlin Aptowicz, and Allan I. Pack. 1997. "Cumulative Sleepiness, Mood Disturbance, and Psychomotor Vigilance Performance Decrements during a Week of Sleep Restricted to 4-5 Hours per Night." Sleep 20 (4): 267-77.

Dorrian, Jillian, Naomi L. Rogers, and David F. Dinges. 2005. "Psychomotor Vigilance Performance: A Neurocognitive Assay Sensitive to Sleep Loss.” In Sleep Deprivation: Clinical Issues, Pharmacology and Sleep Loss Effects, edited by Clete Kushida, 39-70. New York: Marcel Dekker.

Dulmen, Sandra, Emmy Sluijs, Liset Dijk, Denise Ridder, Rob Heerdink, and Jozien Bensing. 2007. "Patient Adherence to Medical Treatment: A Review of Reviews." BMC Health Services Research 7 (1): 55-68.

Duncan, Greg J., Chantelle J. Dowset, Amy Claessens, Katherine Magnuson, Aletha C. Huston, Pamela Klebanov, Linda S. Pagani, et al. 2007. "School Readiness and Later Achievement." Developmental Psychology 43 (6): 1428-46.

Dupas, Pascaline, and Jonathan Robinson. 2013. "Why Don't the Poor Save More? Evidence from Health Savings Experiments." American Economic Review 103 (4): $1138-71$.

Ebenstein, Avraham, Victor Lavy, and Sefi Roth. 2016. "The Long-Run Economic Consequences of High-Stakes Examinations: Evidence from Transitory Variation in Pollution." American Economic Journal: Applied Economics 8 (4): 36-65.

Eccleston, Chris, and Geert Crombez. 1999. "Pain Demands Attention: A CognitiveAffective Model of the Interruptive Function of Pain." Psychological Bulletin 125 (3): 356-66.

Egeland, Jens, Susanne Nordby Johansen, and Torill Ueland. 2009. "Differentiating between ADHD Sub-types on CCPT Measures of Sustained Attention and Vigilance." Scandinavian Journal of Psychology 50 (1): 347-54.

Enmarker, Ingela, Eva Boman, and Staffan Hygge. 2006. "Structural Equation Models of Memory Performance across Noise Conditions and Age Groups." Scandinavian Journal of Psychology 47:449-60.

Ericson, Keith Marzilli. 2017. "On the Interaction of Memory and Procrastination: Implications for Reminders, Deadlines and Empirical Estimation." Journal of the European Economic Association 5 (3): 692-719.

Eriksen, Barbara A., and Charles W. Eriksen. 1974. "Effects of Noise Letters upon the Identification of a Target Letter in a Nonsearch Task." Perception and Psychophysics 16 (1): 143-49.

Evans, Gary W., and Kimberly English. 2002. "The Environment of Poverty: Multiple Stressor Exposure.” Child Development 73 (4): 1238-48.

Evans, Gary W., and Michelle A. Schamberg. 2009. "Childhood Poverty, Chronic Stress, and Adult Working Memory." Proceedings of the National Academy of Sciences USA (PNAS) 106 (16): 6545-49. 
Fafchamps, Marcel, and Agnes R. Quisumbing. 1999. "Human Capital, Productivity, and Labor Allocation in Rural Pakistan." Journal of Human Resources 34 (2): 369-406.

Famulari, Melissa. 1988. "A Household-Based, Nonparametric Test of Demand Theory." Review of Economics and Statistics 77 (2): 372-82.

Fang, Hanming, and Glenn C. Loury. 2005. "Dysfunctional Identities Can Be Rational." American Economic Review 95 (2): 104-11.

Fernald, Lia, and Megan R. Gunnar. 2009. "Effects of a Poverty-Alleviation Intervention on Salivary Cortisol in Very Low-Income Children.” Social Science \& Medicine 68 (12): 2180-89.

Fessler, Daniel M. T., Elizabeth G. Pillsworth, and Thomas J. Flamson. 2004. "Angry Men and Disgusted Women: An Evolutionary Approach to the Influence of Emotions on Risk Taking." Organizational Behavior and Human Decision Processes 95:107-23.

Février, Philippe, and Michael Visser. 2004. "A Study of Consumer Behavior Using Laboratory Data.” Experimental Economics 7 (1): 93-114.

Fisher, Irving. 1930. The Theory of Interest, as Determined by Impatience to Spend Income and Opportunity to Invest It. New York: MacMillan.

Fonseca-Azevedo, Karina, and Suzana Herculano-Houzel. 2012. "Metabolic Constraint Imposes Trade-Off between Body Size and Number of Brain Neurons in Human Evolution." Proceedings of the National Academy of Sciences USA (PNAS), 109 (45): 18571-76.

Food and Agricultural Organization of the United Nations, International Fund for Agricultural Development, and World Food Programme. 2011. The State of Food Insecurity in the World 2011. How does International Price Volatility Affect Domestic Economies and Food Security? Rome: Food and Agriculture Organization Publications.

Fox, R. H., R. Goldsmith, I. F. G. Hampton, and T. J. Hunt. 1967. "Heat Acclimatization by Controlled Hyperthermia in Hot-Dry and Hot-Wet Climates." Journal of Applied Physiology 22 (1): 39-46.

Franco Suglia, Shakira, Charis Gryparis, Robert O. Wright, Joel Schwartz, and R. John Wright. 2008. "Association of Black Carbon with Cognition among Children in a Prospective Birth Cohort Study." American Journal of Epidemiology 167 (3): 280-86.

Frederick, Shane. 2005. "On the Ball: Cognitive Reflection and Decision-Making." Journal of Economic Perspectives 19 (4): 25-42.

Frederick, Shane, George Loewenstein, and Ted O'Donoghue. 2002. "Time Discounting and Time Preference: A Critical Review." Journal of Economic Literature 40 (2): 351-401.

Free, Caroline, Rosemary Knight, Steven Robertson, Robyn Whittaker, Phil Edwards, Weiwei Zhou, Anthony Rodgers, John Cairns, Michael G. Kenward, and Ian Roberts. 2011. "Smoking Cessation Support Delivered via Mobile Phone Text Messaging (txt2stop): A Single-Blind, Randomised Trial." Lancet 378 (9785): 49-55.

Friedman, Naomi P., Akira Miyake, Robin P. Corley, Susan E. Young, John C. DeFries, and John K. Hewitt. 2006. "Not All Executive Functions Are Related to Intelligence." Psychological Science 17 (2): 172-79.

Fudenberg, Drew, and David K. Levine. 2006. "A Dual-Self Model of Impulse Control." American Economic Review 96 (5): 1449-76.

Gabaix, Xavier. 2014. "A Sparsity-Based Model of Bounded Rationality." Quarterly Journal of Economics 129 (4): 1661-710.

2016. "Behavioral Macroeconomics via Sparse Dynamic Programming." NBER Working Paper no. 21848, Cambridge, MA. 
Gabaix, Xavier, and David Laibson. 2006. "Shrouded Attributes, Consumer Myopia, and Information Suppression in Competitive Markets." Quarterly Journal of Economics 121 (2): 505-40.

Gailliot, Matthew T., Roy F. Baumeister, C. Nathan DeWall, Jon K. Maner, E. Ashby Plant, Dianne M. Tice, Lauren E. Brewer, and Brandon J. Schmeichel. 2007. "SelfControl Relies on Glucose as a Limited Energy Source: Willpower Is More Than a Metaphor." Journal of Personality and Social Psychology 92 (2): 325-36.

Gallagher, Kelly Sims, and Erich Muehlegger. 2011. "Giving Green to Get Green? Incentives and Consumer Adoption of Hybrid Vehicle Technology." Journal of Environmental Economics and Management 61 (1): 1-15.

Gaoua, Nadia. 2011. "The Effects of Heat Exposure on Cognitive Performance." Scandinavian Journal of Medicine \& Science in Sports 20 (3): 60-70.

Gawande, Atul. 2004. "On Washing Hands." New England Journal of Medicine 350:1283-86.

Ghio, Andrew J., Chong Kim, and Robert B. Devlin. 2000. "Concentrated Ambient Air Particles Induce Mild Pulmonary Inflammation in Healthy Human Volunteers." American Journal of Respiratory and Critical Care Medicine 162 (3.1): 981-88.

Gibson, Matthew, and Jeffrey Shrader. 2015. "Time Use and the Labor Market: The Wage Returns to Sleep.” Department of Economics Working Paper no. 2015-17, Department of Economics, Williams College.

Giné, Xavier, Dean Karlan, and Jonathan Zinman. 2010. "Put Your Money Where Your Butt Is: A Commitment Contract for Smoking Cessation." American Economic Journal: Applied Economics 2:213-35.

Glass, David C., Jerome E. Singer, and Lucy N. Friedman. 1969. "Psychic Cost of Adaptation to an Environmental Stressor." Journal of Personality and Social Psychology 12 (3): 200-210.

Godefroy, Olivier, Maryline Cabaret, Violaine Petit-Chenal, Jean-Pierre Pruvo, and Marc Rousseaux. 1999. "Control Functions of the Frontal Lobes. Modularity of the Central-Supervisory System?" Cortex 35 (1): 1-20.

Gottfredson, Michael R., and Travis Hirschi. 1990. A General Theory of Crime. Palo Alto, CA: Stanford University Press.

Graff Zivin, Joshua, and Matthew Neidell. 2012. "The Impact of Pollution on Worker Productivity." American Economic Review 102 (7): 3652-73.

Grandner, Michael A., Nirav P. Patel, Philip R. Gehrman, Dawei Xie, Daohang Sha, Terri Weaver, and Nalaka Gooneratne. 2010. "Who Gets the Best Sleep? Ethnic and Socioeconomic Factors Related to Sleep Complaints." Sleep Medicine 11:470-78.

Grant, David A., and Esta A. Berg. 1948. "A Behavioral Analysis of Degree of Reinforcement and Ease of Shifting to New Responses in Weigl-Type Card-Sorting Problem." Journal of Experimental Psychology 38:404-11.

Greenstone, Michael, Janhavi Nilekani, Rohini Pande, Nicholas Ryan, Anant Sudarshan, and Anish Sugathan. 2015. "Lower Pollution, Longer Lives: Life Expectancy Gains If India Reduced Particulate Matter Pollution.” Economic \& Political Weekly 1 (8): 40-46.

Gruber, Jonathan, and Botond Köszegi. 2001. "Is Addiction Rational? Theory and Evidence." Quarterly Journal of Economics 116:1261-303.

Gul, Faruk, and Wolfgang Pesendorfer. 2001. "Temptation and Self-Control." Econometrica 69:1403-35.

- 2004. "Self-Control, Revealed Preferences and Consumption Choice." Review of Economic Dynamics 7 (2): 243-64.

. 2012. “The War of Information.” Review of Economic Studies 79 (2): 707-34. 
Guy, Rebecca, Jane Hocking, Handon Wand, Sam Stott, Hammad Ali, and John Kaldor. 2012. "How Effective Are Short Message Service Reminders at Increasing Clinic Attendance? A Meta-analysis and Systematic Review." Health Services Research 47 (2): 614-32.

Hagger, Martin S., Nikos L. D. Chatzisarantis, H. Alberts, C. O. Anggono, C. Batailler, A. R. Birt, R. Brand, et al. 2016. "A Multilab Preregistered Replication of the Ego-Depletion Effect." Perspectives on Psychological Science 11 (4): 546-73.

Ham, John C., Jacqueline S. Zweig, and Edward Avol. 2011. "Pollution, Test Scores and the Distribution of Academic Achievement: Evidence from California Schools 2002-2008.”http://www.iza.org/conference_files/TAM2012/ham_j1496.pdf.

Handel, Benjamin R. 2013. "Adverse Selection and Inertia in Health Insurance Markets: When Nudging Hurts." American Economic Review 103 (7): 2643-82.

Handel, Benjamin R., and Jonathan T. Kolstad. 2015. "Health Insurance for Humans: Information Frictions, Plan Choice, and Consumer Welfare." American Economic Review 105 (8): 2449-500.

Hanna, Rema, Sendhil Mullainathan, and Joshua Schwartzstein. 2014. "Learning through Noticing: Theory and Evidence from a Field Experiment." Quarterly Journal of Economics 129 (3): 1311-53.

Hasher, Lynn, and Rose T. Zacks. 1998. "Working Memory, Comprehension, and Aging: A Review and a New View." In The Psychology of Learning and Motivation: Advances in Research and Theory, edited by G. H. Bower, 193-225. San Diego, CA: Academic.

—. 2006. "Aging and Long-Term Memory: Deficits Are Not Inevitable." In Lifespan Cognition: Mechanisms of Change, edited by Ellen Bialystock and Fergus I. M. Craik, 162-77. New York: Oxford University Press.

Haushofer, Johannes. 2015. "The Cost of Keeping Track.”Working paper, Princeton University.

Haushofer, Johannes, Sandra Cornelisse, Maayke Seinstra, Ernst Fehr, Marian Joëls, and Tobias Kalenscher. 2013. "No Effects of Psychosocial Stress on Intertemporal Choice." PLOS One 8 (11): e78597.

Haushofer, Johannes, and Ernst Fehr. 2014. "On the Psychology of Poverty." Science 344 (6186): 862-67.

Haushofer, Johannes, Chaning Jang, and John Lynham. 2015. "Stress and Temporal Discounting: Do Domains Matter?” Working paper, Princeton University.

Haushofer, Johannes, and Jeremy Shapiro. 2016. "The Short-Term Impact of Unconditional Cash Transfers to the Poor: Experimental Evidence From Kenya." Quarterly Journal of Economics 131 (4): 1973-2042.

Haynes, R. Brian, Elizabeth Ackloo, Navdeep Sahota, Heather Pauline McDonald, and Xiaomei Yao. 2008. "Interventions for Enhancing Medication Adherence." Cochrane Database of Systematic Reviews 16(2). https://doi.org/10.1002/14651858 .CD000011.pub3.

Heckman, James, and Edward Vytlacil. 2001. "Identifying the Role of Cognitive Ability in Explaining the Level of and Change in the Return of Schooling." Review of Economics and Statistics 83 (1): 1-12.

Hinson, John M., Tina L. Jameson, and Paul Whitney. 2003. "Impulsive Decision Making and Working Memory." Journal of Experimental Psychology: Learning, Memory, and Cognition 29 (2): 298-306.

Hockey, G. Robert J. 1986. "Changes in Operator Efficiency as a Function of Environmental Stress, Fatigue, and Circadian Rhythms." In Handbook of Human Perception and Performance: Vol. 2. Cognitive Processes and Performance, edited by Kenneth R. Boff, Lloyd Kaufman, and James P. Thomas, 1-49. New York: Wiley. 
Hofmann, Wilhelm, Malte Friese, and Fritz Strack. 2009. "Impulse and Self-Control from a Dual-Systems Perspective." Perspectives on Psychological Science 4 (2): $162-76$

Hofmann, Wilhelm, Wolfgang Rauch, and Bertram Gawronski. 2007. "And Deplete Us Not into Temptation: Automatic Attitudes, Dietary Restraint and SelfRegulatory Resources as Determinants of Eating Behavior." Journal of Experimental Social Psychology 43 (1): 497-504.

Horn, John L., and Raymond B. Cattell. 1967. "Age Differences in Fluid and Crystallized Intelligence." Acta Psychologica 26 (1): 107-29.

Hsiang, Solomon M. 2010. "Temperatures and Cyclones Strongly Associated with Economic Production in the Caribbean and Central America." Proceedings of the National Academy of Sciences USA (PNAS) 107 (35): 15367-72.

Hygge, Staffan, Eva Boman, and Ingela Enmarker. 2003. "The Effects of Road Traffic Noise and Meaningful Irrelevant Speech on Different Memory Systems." Scandinavian Journal of Psychology 44:13-21.

Hygge, Staffan, Gary W. Evans, and Monika Bullinger. 2002. "A Prospective Study of Some Effects of Aircraft Noise on Cognitive Performance in Schoolchildren." Psychological Science 13 (5): 469-74.

Intergovernmental Panel on Climate Change. 2014. "Summary for Policymakers." In Climate Change 2014: Impacts, Adaptation, and Vulnerability. Part A: Global and Sectoral Aspects. Contribution of Working Group II to the Fifth Assessment Report of the Intergovernmental Panel on Climate Change, edited by C. B. Field, V. R. Barros, D. J. Dokken, K. J. Mach, M. D. Mastrandrea, T. E. Bilir, M. Chatterjee, et al., 1-32. Cambridge: Cambridge University Press.

Inzlicht, Michael, and Brandon J. Schmeichel. 2012. "What Is Ego Depletion? Toward a Mechanistic Revision of the Resource Model of Self-Control." Perspectives on Psychological Science 7 (5): 450-63.

Irgens-Hansen, Kaja, Hilde Gundersen, Erlend Sunde, Valborg Baste, Anette Harris, Magne Bråtveit, and Bente E. Moen. 2015. "Noise Exposure and Cognitive Performance: A Study on Personnel on Board Royal Norwegian Navy Vessels." Noise \& Health 17 (78): 320-27.

Jaeggi, Susanne M., Martin Buschkuehl, Walter J. Perrig, and Beat Meier. 2010. "The Concurrent Validity of the N-Back Task as a Working Memory Measure." Memory 18 (4): 394-412.

Jaeggi, Susanne M., Ria Seewer, Arto C. Nirkko, Doris Eckstein, Gerhard Schroth, Rudolf Groner, and Klemens Gutbrod. 2003. "Does Excessive Memory Load Attenuate Activation in the Prefrontal Cortex? Load-Dependent Processing in Single and Dual Tasks: Functional Magnetic Resonance Imaging Study." Neuroimage 19 (2): $210-25$.

Jalan, Jyotsna, and Martin Ravallion. 2002. "Geographic Poverty Traps? A Micro Model of Consumption Growth in Rural China." Journal of Applied Econometrics 17 (4): 329-46.

James, William. 1890. The Principles of Psychology. New York: Henry Holt.

Jamir, Limalemla, Baridalyne Nongkynrih, and Sanjeev Kumar Gupta. 2014. "Community Noise Pollution in Urban India: Need for Public Health Action." Indian Journal of Community Medicine 39 (1): 8-12.

Jamrah, Ahmad, Abbas Al-Omari, and Reem Sharabi. 2006. "Evaluation of Traffic Noise Pollution in Amman, Jordan." Environmental Monitoring and Assessment 120 (1): 499-525.

Jaušovec, Norbert. 1991. "Flexible Strategy Use: A Characteristic of Gifted Problem Solving." Creativity Research Journal 4 (4): 349-66. 
1994. Flexible Thinking: An Explanation for Individual Differences. New York: Hampton Press.

Johnson, Eric J., and Daniel Goldstein. 2003. "Do Defaults Save Lives?" Science 302 (5649): 1338-39.

Jones, Benjamin F., and Benjamin A. Olken. 2010. "Climate Shocks and Exports." American Economic Review 100 (2): 454-59.

Judge, Timothy A., Charlice Hurst, and Lauren S. Simon. 2009. "Does It Pay to Be Smart, Attractive, or Confident (or All Three)? Relationships among General Mental Ability, Physical Attractiveness, Core Self-Evaluations, and Income." Journal of Applied Psychology 94 (3): 742-55.

Jurado, María Beatriz, and Mónica Rosselli. 2007. "The Elusive Nature of Executive Functions: A Review of Our Current Understanding." Neuropsychology Review 17 (3): 213-33.

Kandasamya, Narayanan, Ben Hardy, Lionel Page, Markus Schaffner, Johann Graggaber, Andrew S. Powlson, Paul C. Fletcher, Mark Gurnell, and John Coates. 2013. "Cortisol Shifts Financial Risk Preferences." Proceedings of the National Academy of Sciences USA (PNAS) 111 (9): 3608-13.

Kandel, Eric, James H. Schwartz, and Thomas Jessell. 2000. Principles of Neural Science. New York: McGraw-Hill.

Kane, Michael J., Andrew R. A. Conway, Timothy K. Miura, and Gregory J. H. Colflesh. 2007. "Working Memory, Attention Control, and the N-Back Task: A Question of Construct Validity." Journal of Experimental Psychology: Learning, Memory, and Cognition 33 (3): 615-22.

Kane, Michael J., and Randall W. Engle. 2002. "The Role of Pre-frontal Cortex in Working-Memory Capacity, Executive Attention, and General Fluid Intelligence: An Individual-Differences Perspective." Psychonomic Bulletin and Review 9 (4): 637-71.

Kaplan, Stephen, and Marc G. Berman. 2010. "Directed Attention as a Common Resource for Executive Functioning and Self-Regulation." Perspectives on Psychological Science 5 (1): 43-57.

Karlan, Dean, Margaret McConnell, Sendhil Mullainathan, and Jonathan Zinman. 2016. "Getting to the Top of Mind: How Reminders Increase Saving." Management Science. https://doi.org/10.1287/mnsc.2015.2296.

Karlan, Dean, Melanie Morten, and Jonathan Zinman. Forthcoming. "A Personal Touch: Text Messaging for Loan Repayment.” Behavioral Science and Policy.

Karlan, Dean, and Sendhil Mullainathan. 2010. "Debt Cycles." Unpublished manuscript.

Kaur, Supreet, Michael Kremer, and Sendhil Mullainathan. 2015. "Self-Control at Work.” Journal of Political Economy 123 (6): 1227-77.

Kilby, Angela. 2015. "Opioids for the Masses: Welfare Tradeoffs in the Regulation of Narcotic Pain Medications." Job Market Paper, Department of Economics, Massachusetts Institute of Technology. http://economics.mit.edu/files/11150.

Killgore, William D. S. 2010. "Effects of Sleep Deprivation on Cognition." Progress in Brain Research 185:105-29.

Kimberg, Daniel Y., Mark D'Esposito, and Martha J. Farah. 1997. "Cognitive Functions in the Prefrontal Cortex: Working Memory and Executive Control." Current Directions in Psychological Science 6 (6): 185-92.

King, Jacqueline. 2004. "Missed Opportunities: Students Who Do Not Apply for Financial Aid." American Council on Education Issue Brief. http://www.acenet.edu /news-room/Pages/Missed-Opportunities-Students-Who-Do-Not-Apply-for.aspx.

Kirchner, Wayne K. 1958. "Age Differences in Short-Term Retention of Rapidly Changing Information.” Journal of Experimental Psychology 55 (4): 352-58. 
Kjellstrom, Tord, Ingvar Holmer, and Bruno Lemke. 2009. "Workplace Heat Stress, Health and Productivity - An Increasing Challenge for Low and Middle-Income Countries during Climate Change." Global Health Action 2 (1). https://doi .org/10.3402/gha.v2i0.2047.

Knox, Alan B. 1997. Adult Development and Learning. San Francisco: Jossey-Bass.

Koppel, Lina, David Andersson, India Morrison, Kinga Posadzdy, Daniel Västfjäll, and Gustav Tinghög. 2017. "The Effect of Acute Pain on Risky and Intertemporal Choice.” Experimental Economics 20 (4): 878-93.

Köszegi, Botond, and Adam Szeidl. 2013. "A Model of Focusing in Economic Choice." Quarterly Journal of Economics 128 (1): 53-104.

Kraay, Aart, and David McKenzie. 2014. "Do Poverty Traps Exist? Assessing the Evidence." Journal of Economic Perspectives 28 (3): 127-48.

Kraay, Aart, and Claudio Raddatz. 2007. "Poverty Traps, Aid, and Growth." Journal of Development Economics 82 (2): 315-47.

Kremer, Michael, Edward Miguel, Sendhil Mullainathan, Clair Null, and Alix P. Zwane. 2009. "Making Water Safe: Price, Persuasion, Peers, Promoters, or Product Design.” Unpublished manuscript.

Krishna, Santosh, Suzanne Austin Boren, and E. Andrew Balas. 2009. "Healthcare via Cell Phones: A Systematic Review." Telemedicine and e-Health 15 (3): 231-40.

Kuhnen, Camelia M., and Brian Knutson. 2005. "The Neural Basis of Financial Risk Taking." Neuron 47 (5): 763-70.

Laibson, David. 1997. "Golden Eggs and Hyperbolic Discounting." Quarterly Journal of Economics 112 (2): 443-78.

Lauderdale, Diane S., Kristen L. Knutson, Lijing L. Yan, Kiang Liu, and Paul J. Rathouz. 2008. "Self-Reported and Measured Sleep Duration: How Similar Are They?" Epidemiology 19 (6): 838-45.

Lavie, Nilli, Aleksandra Hirst, Jan W. de Fockert, and Essi Viding. 2004. "Load Theory of Selective Attention and Cognitive Control." Journal of Experimental Psychology 133 (3): 339-54.

Lavy, Victor, Avraham Ebenstein, and Sefi Roth. 2014. "The Impact of Short Term Exposure to Ambient Air Pollution on Cognitive Performance and Human Capital Formation.” NBER Working Paper no. 20648, Cambridge, MA.

Leibenstein, Harvey. 1957. "The Theory of Underemployment in Backward Economies." Journal of Political Economy 65 (2): 91-103.

Lerner, Jennifer S., Deborah A. Small, and George Loewenstein. 2004. "Heart Strings and Purse Strings: Carryover Effects of Emotions on Economic Decisions." Psychological Science 15 (5): 337-41.

Letzler, Robert, and Joshua Tasoff. 2014. "Everyone Believes in Redemption: Nudges and Overoptimism in Costly Task Completion." Journal of Economic Behavior \& Organization 107:107-22.

Lezak, Muriel D. 1983. Neuropsychological Assessment. New York: Oxford University Press.

Lezak, Muriel D., Diane B. Howieson, and David W. Loring. 2004. Neuropsychological Assessment, 4th ed. New York: Oxford University Press.

Li, Leah, Chris Power, Shona Kelly, Clemens Kirschbaum, and Clyde Hertzman. 2007. "Life-Time Socio-economic Position and Cortisol Patterns in Mid-life." Psychoneuroendocrinology 32:824-33.

Lichtenberger, Elizabeth O., and Alan S. Kaufman. 2009. Essentials of WAIS-IV Assessment. Hoboken, NJ: John Wiley.

Lighthall, Nichole R., Mara Mather, and Marissa A. Gorlick. 2009. "Acute Stress Increases Sex Differences in Risk Seeking in the Balloon Analogue Risk Task." PLOS One 4 (7): e6002. 
Lim, Julian, and David Dinges. 2008. "Sleep Deprivation and Vigilant Attention." Annals of the New York Academy of Sciences 1129 (1): 305-22.

2010. "A Meta-analysis of the Impact of Short-Term Sleep Deprivation on Cognitive Variables." Psychological Bulletin 136 (3): 375-89.

Lim, Julian, Wen-Chau Wu, Jiongjiong Wang, John A. Detre, David F. Dinges, and Hengyi Rao. 2010. "Imaging Brain Fatigue from Sustained Mental Workload: An ASL Perfusion Study of the Time-on-Task Effect." Neuroimage 49 (4): 3426-35.

Lim, Stephen S., Theo Vos, Abraham D. Flaxman, Goodarz Danaei, Kenji Shibuya, Heather Adair-Rohani, and Markus Amann. 2012. "A Comparative Risk Assessment of Burden of Disease and Injury Attributable to 67 Risk Factors and Risk Factor Clusters in 21 Regions, 1990-2010: A Systematic Analysis for the Global Burden of Disease Study 2010.” Lancet 380 (9859): 2224-60.

Lu, Chen-Lui, and Robert W. Proctor. 1995. "The Influence of Irrelevant Location Information on Performance: A Review of the Simon and Spatial Stroop Effects." Psychonomic Bulletin and Review 2 (2): 174-207.

Lund, Crick, Alison Breen, Alan J. Flisher, Ritsuko Kakuma, Joanne Corrigall, John A. Joska, Leslie Swartz, and Vikram Patel. 2010. "Poverty and Common Mental Disorders in Low and Middle Income Countries: A Systematic Review." Social Science \& Medicine 71 (3): 517-28.

Luo, Yulei. 2008. "Consumption Dynamics under Information Processing Constraints." Review of Economic Dynamics 11 (2): 366-85.

Lupien, Sonia J., Suzanne King, Michael J. Meaney, and Bruce S. McEwan. 2001. "Can Poverty Get under Your Skin? Basal Cortisol Levels and Cognitive Function in Children from Low and High Socioeconomic Status." Developmental Psychopathology 13:651-74.

Lyon, G. Reid, and Norman A. Krasnegor. 1996. Attention, Memory, and Executive Function. Baltimore: Paul H. Brookes Publishing.

Maćkowiak, Bartosz, and Mirko Wiederholt. 2009. "Optimal Sticky Prices under Rational Inattention." American Economic Review 99 (3): 769-803.

_. 2015. "Business Cycle Dynamics under Rational Inattention." Review of Economic Studies 82 (4): 1502-32.

Mackworth, Jane F. 1968. "Vigilance, Arousal, and Habituation." Psychological Review 75 (4): 308-22.

MacLeod, Colin M. 1991. "Half a Century of Research on the Stroop Effect: An Integrative Review." Psychological Bulletin 109 (2): 163-203.

MacLeod, Colin M., Michael D. Dodd, Erin D. Sheard, Daryl E. Wilson, and Uri Bibi. 2003. "In Opposition to Inhibition." In The Psychology of Learning and Motivation, vol. 43, edited by Brian H. Ross, 163-214. Amsterdam: Elsevier Science.

Madrian, Brigitte C., and Dennis F. Shea. 2001. "The Power of Suggestion: Inertia in 401(k) Participation and Savings Behavior." Quarterly Journal of Economics 116 (4): 1149-87.

Mani, Anandi, Sendhil Mullainathan, Eldar Shafir, and Jiaying Zhao. 2013. "Poverty Impedes Cognitive Function." Science 341:976-80.

Martin, Matthew M., and Carolyn M. Anderson. 1998. "The Cognitive Flexibility Scale: Three Validity Studies." Communication Reports 11 (1): 1-9.

Martin, Matthew M., and Rebecca B. Rubin. 1995. "A New Measure of Cognitive Flexibility." Psychological Reports 76:623-26.

Matějka, Filip. 2016. "Rationally Inattentive Seller: Sales and Discrete Pricing." Review of Economic Studies 83 (3): 1125-55.

Mather, Mara, Marissa A. Gorlick, and Nichole R. Lighthall. 2009. "To Brake or Accelerate When the Light Turns Yellow? Stress Reduces Older Adults' Risk Taking in a Driving Game.” Psychological Science 20 (2): 174-76. 
Mazloumi, Adel, Farideh Golbabaei, Somayeh M. Khani, Zeinab Kazemi, Mostafa Hosseini, Marzieh Abbasinia, and Somayeh F. Dehghan. 2014. "Evaluating Effects of Heat Stress on Cognitive Function among Workers in a Hot Industry." Health Promotion Perspectives 4 (2): 240-46.

McGranahan, Gordon, and Frank Murray, eds. 2003. Air Pollution and Health in Rapidly Developing Countries. Abingdon-on-Thames, UK: Routledge.

McKenna, Benjamin, David L. Dickinson, Henry J. Orff, and Sean Drummond. 2007. "The Effects of One-Night Sleep Deprivation on Known-Risk and AmbiguousRisk Decisions.” Journal of Sleep Research 16 (3): 245-52.

Mehdi, Mohammed Raza, Minho Kim, Jeong Chang Seong, and Mudassar Hassan Arsalan. 2011. "Spatio-temporal Patterns of Road Traffic Noise Pollution in Karachi, Pakistan.” Environment International 37 (1): 97-104.

Miller, Earl K., and Jonathan D. Cohen. 2001. "An Integrative Theory of Prefrontal Cortex Function." Annual Review of Neuroscience 24 (1): 167-202.

Miller, George A. 1956. "The Magic Number Seven, Plus or Minus Two: Some Limits on Our Capacity for Processing Information." Psychological Review 63 (2): 81-97.

Mirrlees, James A. 1975. A Pure Theory of Underdeveloped Economies, Using a Relationship between Consumption and Productivity. New Haven, CT: Yale University Press.

Mischel, Walter, Yuichi Shoda, and Monica L. Rodriguez. 1989. "Delay of Gratification in Children." Science 244 (4907): 933-38.

Miyake, Akira, Naomi P. Friedman, Michael J. Emerson, Alexander H. Witzki, Amy Howerter, and Tor D. Wager. 2000. "The Unity and Diversity of Executive Functions and Their Contributions to Complex 'Frontal Lobe' Tasks: A Latent Variable Analysis." Cognitive Psychology 41 (1): 49-100.

Mondria, Jordi. 2010. "Portfolio Choice, Attention Allocation, and Price Comovement." Journal of Economic Theory 145 (5): 1837-64.

Moriarty, Orla, Brian E. McGuire, and David P. Finn. 2011. "The Effect of Pain on Cognitive Function: A Review of Clinical and Preclinical Research." Progress in Neurobiology 93 (3): 385-404.

Mullainathan, Sendhil. 2002. "A Memory-Based Model of Bounded Rationality." Quarterly Journal of Economics 117 (3): 735-74.

Mullainathan, Sendhil, and Eldar Shafir. 2013. Scarcity: Why Having Too Little Means So Much. New York: Henry Holt.

Mullane, Jennifer C., Penny V. Corkum, Raymond M. Klein, and Elizabeth McLaughlin. 2009. "Interference Control in Children with and without ADHD: A Systematic Review of Flanker and Simon Task Performance." Child Neuropsychology 15 (4): 321-42.

Munakata, Yuko, Seth A. Herd, Christopher H. Chatham, Brendan E. Depue, Marie T. Banich, and Randall C. O'Reilly. 2011. "A Unified Framework for Inhibitory Control." Trends in Cognitive Science 15 (10): 453-59.

Muraven, Mark, and Roy F. Baumeister. 2000. "Self-Regulation and Depletion of Limited Resources: Does Self-Control Resemble a Muscle?" Psychological Bulletin 126 (2): 247-59.

Muraven, Mark, Dianne M. Tice, and Roy Baumeister. 1998. "Self-Control as a Limited Resource: Regulatory Depletion Patterns." Journal of Personality and Social Psychology 74 (3): 774-89.

Murnane, Richard J., John B. Willett, and Frank Levy. 1995. "The Growing Importance of Cognitive Skills in Wage Determination." Review of Economics and Statistics 2:251-66.

Nes, Lise S., Abbey R. Roach, and Suzanne C. Segerstrom. 2009. "Executive Functions, Self-Regulation, and Chronic Pain: A Review." Annals of Behavioral Medicine 37 (2): 173-83. 
Nideffer, Robert M. 1976. "Test of Attentional and Interpersonal Style." Journal of Personality and Social Psychology 34:394-404.

Nuland, Sherwin B. 2004. The Doctors' Plague: Germs, Childbed Fever, and the Strange Story of Ignac Semmelweis. New York: W. W. Norton.

O’Donoghue, Ted, and Matthew Rabin. 1999. "Doing It Now or Later." American Economic Review 89 (1): 103-24.

2001. "Choice and Procrastination." Quarterly Journal of Economics 116 (1): $121-60$.

Okuda, Shawn M., Mark A. Runco, and Dale E. Berger. 1991. "Creativity and the Finding and Solving of Real-World Problems." Journal of Psychoeducational Assessment 9 (1): 45-53.

Oyedepo, Olayinka S., and Abdullahi A. Saadu. 2009. "A Comparative Study of Noise Pollution Levels in Some Selected Areas in Ilorin Metropolis, Nigeria." Environmental Monitoring and Assessment 158:155-67.

Ozer, Emily, Lia Fernald, Ann Weber, Emily Flynn, and Tyler VanderWeele. 2011. "Does Alleviating Poverty Affect Mothers' Depressive Symptoms? A Quasiexperimental Investigation of Mexico's Oportunidades Programme." International Journal of Epidemiology 40 (6): 1565-76.

Pashler, Harold. 1998. The Psychology of Attention. Cambridge, MA: MIT Press.

Patel, Nirav P., Michael A. Grandner, Dawei Xie, Charles C. Branas, and Nalaka Gooneratne. 2010. "Sleep Disparity' in the Population: Poor Sleep Quality Is Strongly Associated with Poverty and Ethnicity." BMC Public Health 10:1-11.

Pechmann, Cornelia, and Tim Silk. 2013. "Policy and Research Related to Consumer Rebates: A Comprehensive Review." Journal of Public Policy \& Marketing 32 (2): 250-70.

Peterson, Steven, and Michael I. Posner. 2012. "The Attention System of the Human Brain: 20 Years After." Annual Review of Neuroscience 35 (1): 73-89.

Petrides, Michael, Bessie Alivisatos, Alan C. Evans, and Ernst Meyer. 1993. "Dissociation of Human Mid-dorsolateral from Posterior Dorsolateral Frontal Cortex in Memory Processing." Proceedings of the National Academy of Sciences USA (PNAS) 90:873-77.

Petrides, Michael, and Brenda Milner. 1982. "Deficits on Subject-Ordered Tasks after Frontal- and Temporal-Lobe Lesions in Man.” Neuropsychologia 20:249-62.

Phelps, Edmund S., and Robert A. Pollak. 1968. "On Second-Best National Saving and Game-Equilibrium Growth." Review of Economic Studies 35 (2): 185-99.

Phelps, Elizabeth A. 2006. "Emotion and Cognition: Insights from Studies of the Human Amygdala." Annual Review of Psychology 57 (1): 27-53.

Philibert, Ingrid. 2005. "Sleep Loss and Performance in Residents and Nonphysicians: A Meta-analytic Examination.” Sleep 28 (11): 1392-402.

Poleshuck, Ellen L., and Carmen R. Green. 2008. "Socioeconomic Disadvantage and Pain." Pain 136:235-38.

Pope, C. Arden. 2000. "Epidemiology of Fine Particular Air Pollution and Human Health: Biologic Mechanisms and Who's at Risk?" Environmental Health Perspectives 108 (4): 713-23.

Pop-Eleches, Cristian, Harsha Thirumurthy, James P. Habyarimana, Joshua G. Zivin, Markus P. Goldstein, Damien de Walque, Leslie MacKeen, et al. 2011. "Mobile Phone Technologies Improve Adherence to Antiretroviral Treatment in a Resource-Limited Setting: A Randomized Controlled Trial of Text Message Reminders." AIDS 25 (6): 825-34.

Porcelli, Anthony J., and Mauricio R. Delgado. 2009. "Acute Stress Modulates Risk Taking in Financial Decision Making.” Psychological Science 20 (3): 278-83. 
Power, Melinda C., Marc G. Weisskopf, Stacey E. Alexeeff, Brent A. Coull, Avron Spiro III, and Joel Schwartz. 2011. "Traffic-Related Air Pollution and Cognitive Function in a Cohort of Older Men." Environmental Health Perspectives 119 (5): 682-87.

Prabhakaran, Vivek, Jennifer A. L. Smith, John E. Desmond, Gary H. Glover, and John D. E. Gabrieli. 1997. "Neural Substrates of Fluid Reasoning: An fMRI Study of Neocortical Activation during Performance of the Raven's Progressive Matrices Test." Cognitive Psychology 33 (1): 43-63.

Pratt, Travis C., and Francis T. Cullen. 2000. "The Empirical Status of Gottfredson and Hirschi's General Theory of Crime: A Meta-analysis." Criminology 38 (3): 931-64.

Psacharopoulos, George, and Eduardo Velez. 1992. "Does Training Pay Independent of Education? Some Evidence from Colombia." International Journal of Educational Research 17 (6): 629-43.

Psychology Experiment Building Language (PEBL). 2008-2010. Berg's Card Sorting Test. http://pebl.sourceforge.net/wiki/index.php/Berg's_Card_Sorting_Test.

Radakovic, Sonja S., Jelena Maric, Maja Surbatovic, Slavica Radjen, Elka Stefanova, Nebojsa Stankovic, and Nikola Filipovic. 2007. "Effects of Acclimation on Cognitive Performance in Soldiers during Exertional Heat Stress." Military Medicine 172 (2): 133-36.

Raven, John C. 1936. "Mental Tests Used in Genetic Studies: The Performance of Related Individuals on Tests Mainly Educative and Mainly Reproductive." Master's thesis, University of London.

2000. "The Raven's Progressive Matrices: Change and Stability over Culture and Time." Cognitive Psychology 41 (1): 1-48.

Robertson, Ian H., Tom Manly, Jackie Andrade, Bart T. Baddeley, and Jenny Yiend. 1997. "'Oops!': Performance Correlates of Everyday Attentional Failures in Traumatic Brain Injured and Normal Subjects.” Neuropsychologia 35 (6): 747-58.

Roehrs, Timothy, Lori Merlotti, Nancie Petrucelli, Edward Stepanski, and Thomas Roth. 1994. "Experimental Sleep Fragmentation." Sleep 17 (5): 438-43.

Rothbart, Mary K., and Michael I. Posner. 1985. "Temperament and the Development of Self-Regulation." In The Neuropsychology of Individual Differences: A Developmental Perspective, edited by Lawrence C. Hartlage and Cathy F. Tezrow, 93-123. New York: Springer US.

Runco, Mark A., and Shawn M. Okuda. 1991. "The Instructional Enhancement of the Flexibility and Originality Scores of Divergent Thinking Tests." Applied Cognitive Psychology 5 (5): 435-551.

Sachs, Jeffrey. 2005. The End of Poverty: Economic Possibilities for Our Time. New York: Penguin.

- 2014. "The Case for Aid." Foreign Policy, Jan. 21. http://foreignpolicy.com /2014/01/21/the-case-for-aid/.

Sadeh, Avi, Reut Gruber, and Amiram Raviv. 2002. "Sleep, Neurobehavioral Functioning, and Behavior Problems in School-Age Children." Child Development 73 (2): 405-17.

Saridjana, Nathalie S., Anja C. Huizink, Jitske A. Koetsier, Vincent W. Jaddoe, Johan P. Mackenbach, Albert Hofman, Clemens Kirschbaum, Frank C. Verhulst, and Henning Tiemeier. 2010. "Do Social Disadvantage and Early Family Adversity Affect the Diurnal Cortisol Rhythm in Infants? The Generation R Study." Hormones and Behavior 57 (2): 247-54.

Schilbach, Frank. 2017. "Alcohol and Self-Control: A Field Experiment in India." Working paper, Department of Economics, Massachusettes Institute of Technology. 
Schilbach, Frank, Heather Schofield, and Sendhil Mullainathan. 2016. "The Psychological Lives of the Poor." American Economic Review Papers \& Proceedings 106 (5): 435-40.

Schofield, Heather. 2014. "The Economic Costs of Low Caloric Intake: Evidence from India." Working paper, Harvard University.

Schwartzstein, Joshua. 2014. "Selective Attention and Learning." Journal of the European Economic Association 12 (6): 1423-52.

Scott, Jonathon P. R., Lars R. McNaughton, and Remco C. J. Polman. 2006. "Effects of Sleep Deprivation and Exercise on Cognitive, Motor Performance, and Mood." Physiology and Behavior 87 (2): 396-408.

Seaton, Anthony, William MacNee, Ken Donaldson, and David Godden. 1995. "Particulate Air Pollution and Acute Health Effects." Lancet 345 (8943): 176-78.

Sherrod, Drury R. 1974. "Crowding, Perceived Control, and Behavioral Aftereffects." Journal of Applied Social Psychology 4 (2): 171-86.

Shiv, Baba, and Alexander Fedorikhin. 1999. "Heart and Mind in Conflict: The Interplay of Affect and Cognition in Consumer Decision Making." Journal of Consumer Research 26 (3): 278-92.

Simmons, Shona E., Brian K. Saxby, Francis P. McGlone, and David A. Jones. 2008. "The Effect of Passive Heating and Head Cooling on Perception, Cardiovascular Function and Cognitive Performance in the Heat." European Journal of Applied Physiology 104 (2): 271-80.

Sims, Christopher A. 1998. "Stickiness." Carnegie-Rochester Conference Series on Public Policy 49 (1): 317-56.

.2003. "Implications of Rational Inattention." Journal of Monetary Economics 50:665-90.

. 2006. "Rational Inattention: Beyond the Linear-Quadratic Case." American Economic Review Papers and Proceedings 96 (2): 158-63.

Sippel, Reinhard. 1997. "An Experiment on the Pure Theory of Consumer's Behaviour.” Economic Journal 107 (444): 1431-44.

Stansfeld, Stephen A., Birgitta Berglund, Charlotte Clark, Isabel Lopez-Barrio, Peter Fischer, Evy Ohrstrom, Mary M. Haines, J. Head, Staffan Hygge, Irene van Kamp, and Bernard F. Berry. 2005. "Aircraft and Road Traffic Noise and Children's Cognition and Health: A Cross-National Study." Lancet 365 (9475): 1942-49.

Steele, Claude M., and Robert A. Josephs. 1990. "Alcohol Myopia: Its Prized and Dangerous Effects." American Psychologist 45 (8): 921-33.

Sternberg, Robert J., and Karin Sternberg. 2011. Cognitive Psychology, 6th ed. Boston: Cengage Learning.

Stiglitz, Joseph E. 1976. "The Efficiency Wage Hypothesis, Surplus Labour, and the Distribution of Income in LDCs.” Oxford Economic Papers 28 (2): 185-207.

Stroop, John Ridley. 1935. "Studies of Interference in Serial Verbal Reactions." Journal of Experimental Psychology 18 (6): 643-62.

Strotz, Robert. 1956. "Myopia and Inconsistency in Dynamic Utility Maximization." Review of Economic Studies 23 (3): 165-80.

Stuss, Donald T., and Michael P. Alexander. 2000. "Executive Functions and the Frontal Lobes: A Conceptual View." Psychological Research 63 (1): 289-98.

Suchy, Yana. 2009. "Executive Functioning: Overview, Assessment, and Research Issues for Non-neuropsychologists." Annals of Behavioral Medicine 37 (2): 106-16.

Szalma, James L., and Peter A. Hancock. 2011. "Noise Effects on Human Performance: A Meta-analytic Synthesis.” Psychological Bulletin 137 (4): 682-707.

Tchanturia, Kate, Helen Davies, Marion Roberts, Amy Harrison, Michiko Nakazato, Ulrike Schmidt, Janet Treasure, and Robin Morris. 2012. "Poor Cognitive 
Flexibility in Eating Disorders: Examining the Evidence Using the Wisconsin Card Sorting Task." PLOS One 7 (1): e28331.

Thaler, Richard, and Hersh M. Shefrin. 1981. "An Economic Theory of SelfControl." Journal of Political Economy 89 (2): 392-406.

Thurston, Becky J., and Mark A. Runco. 1999. "Flexibility." In Encyclopedia of Creativity, edited by Mark A. Runco and Steven R. Pritzker, 729-31. San Diego, CA: Academic Press.

Torrance, E. Paul. 1974. Torrance Tests of Creative Thinking: Norms and Technical Manual. Bensenville, IL: Scholastic Test Services.

Treisman, Anne M., and Garry Gelade. 1980. "A Feature-Integration Theory of Attention." Cognitive Psychology 12:97-136.

Tzivian, Lilian, Angela Winkler, Martha Dlugaj, Tamara Schikowski, Mohammad Vossoughi, Kateryna Fuks, Gudrun Weinmayr, and Barbara Hoffmann. 2015. "Effect of Long-Term Outdoor Air Pollution and Noise on Cognitive and Psychological Functions in Adults." International Journal of Hygiene and Environmental Health 218 (1): 1-11.

Unterrainer, Josef M., Benjamin Rahm, Christoph P. Kaller, Rainer Leonhart, C. Meier, C. Müller, K. Quiske, K. Hoppe-Seyler, and U. Halsband. 2004. "Planning Abilities and the Tower of London: Is This Task Measuring a Discrete Cognitive Function?" Journal of Clinical and Experimental Neuropsychology 26 (6): 846-56.

US Army Institute of Environmental Medicine. 1987. "Nutritional Status and Physical and Mental Performance of Special Operations Soldiers Consuming the Ration, Lightweight, or the Meal, Ready-to-Eat Military Field Ration during a 30-Day Field Training Exercise." Technical Report no. T7-87, AD A179 553, Natick, MA, US Army Research Institute of Environmental Medicine.

US Department of Transportation (USDT). 2008. National Motor Vehicle Crash Causation Survey. US Department of Transportation, National Highway Traffic Safety Administration, DOT HS 811 059: 1-31.

Van Dongen, Greg M., Janet M. Mullington, and David F. Dinges. 2003. "The Cumulative Cost of Additional Wakefulness: Dose-Response Effects on Neurobehavioral Functions and Sleep Physiology from Chronic Sleep Restriction and Total Sleep Deprivation." Sleep 26 (2): 117-26.

Van Nieuwerburgh, Stijn, and Laura Veldkamp. 2009. "Information Immobility and the Home Bias Puzzle.” Journal of Finance 64 (3): 1187-215.

Vervloet, Marcia, Annemiek J. Linn, Julia C. M. van Weert, Dinny H. de Bakker, Marcel L. Bouvy, and Liset van Dijk. 2012. "The Effectiveness of Interventions Using Electronic Reminders to Improve Adherence to Chronic Medication: A Systematic Review of the Literature." Journal of the American Medical Informatics Association 19:696-704.

Vogl, Tom S. 2014. "Height, Skills, and Labor Market Outcomes in Mexico." Journal of Development Economics 107:84-96.

von Hippel, William, and Karen Gonsalkorale. 2005. "'That Is Bloody Revolting!'Inhibitory Control of Thoughts Better Left Unsaid." Psychological Science 16 (7): 497-500.

Wachtel, Paul L. 1976. "Conceptions of Broad and Narrow Attention." Psychological Bulletin 68 (6): 417-29.

Ward, Andrew, and Traci Mann. 2000. "Don't Mind If I Do: Disinhibited Eating under Cognitive Load." Journal of Personality and Social Psychology 78 (4): 753-63.

Wechsler, David. 2008. Wechsler Adult Intelligence Scale, 4th ed. San Antonio, TX: Psychological Corporation. 
Weuve, Jennifer, Robin C. Puett, Joel Schwartz, Jeff D. Yanosky, Francine Laden, and Francine Grodstein. 2012. "Exposure to Particulate Air Pollution and Cognitive Decline in Older Women." Archives of Internal Medicine 172 (3): 219-27.

Wiebe, Sandra A., Angela F. Lukowski, and Patricia J. Bauer. 2010. "Sequence Imitation and Reaching Measures of Executive Control: A Longitudinal Examination in the Second Year of Life." Developmental Neuropsychology 35:522-38.

Woodford, Michael. 2012. "Inattentive Valuation and Reference-Dependent Choice." Working paper, Columbia University.

World Bank. 2015. World Development Indicators. Washington, DC: World Bank.

World Health Organization (WHO). 2001. World Health Report 2001: Mental Health: New Understanding, New Hope. Geneva: World Health Organization.

_. 2014. "Seven Million Premature Deaths Annually Linked to Air Pollution." Accessed September 5, 2016. http://www.who.int/mediacentre/news/releases/2014 /air-pollution/en/. . 2016. "Fact Sheet on Depression.” Accessed September 5, 2016. http://www .who.int/mediacentre/factsheets/fs369/en/.

Yates, Frances A. 1966. The Art of Memory. Chicago: University of Chicago Press. Zannin, Paulo Henrique Trombetta, Fabiano Belisário Diniz, and Wiliam Alves Barbosa. 2002. "Environmental Noise Pollution in the City of Curitiba, Brazil." Applied Acoustics 63 (4): 351-58. 